\title{
Basel Committee on Banking Supervision
}

\section{Range of practices and issues in economic capital frameworks}

March 2009 

Requests for copies of publications, or for additions/changes to the mailing list, should be sent to:

Bank for International Settlements

Press \& Communications

$\mathrm{CH}-4002$ Basel, Switzerland

E-mail: publications@bis.org

Fax: +41612809100 and +41612808100

(C) Bank for International Settlements 2008. All rights reserved. Brief excerpts may be reproduced or translated provided the source is stated.

ISBN print: 92-9131-777-2

ISBN web: 92-9197-777-2 



\section{Table of Contents}

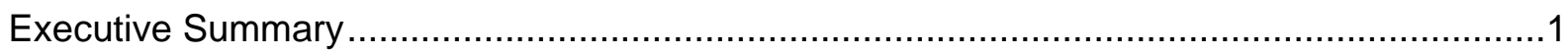

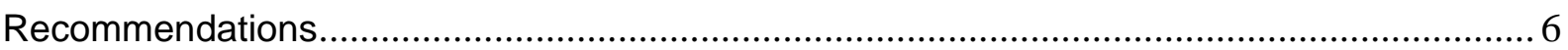

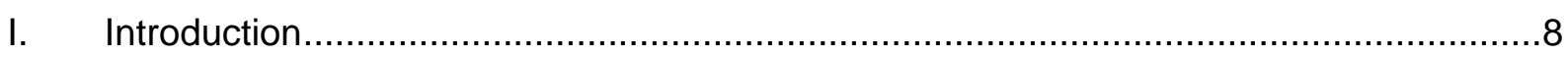

II. Use of economic capital measures and governance ..............................................

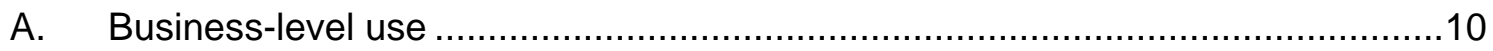

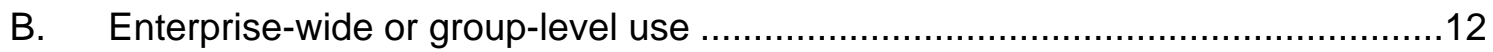

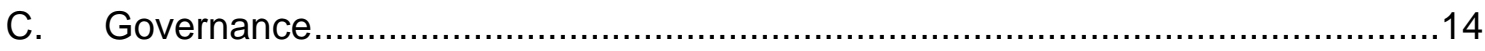

D. Supervisory concerns relating to use of economic capital and governance ........16

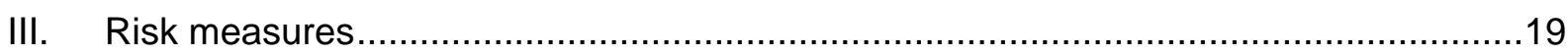

A. Desirable characteristics of risk measures...................................................

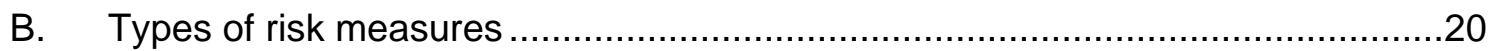

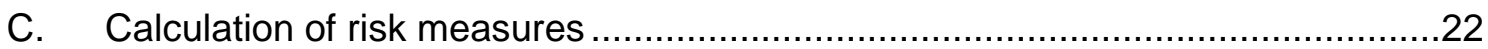

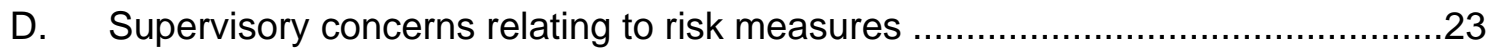

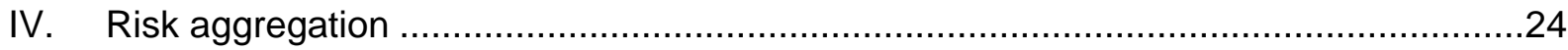

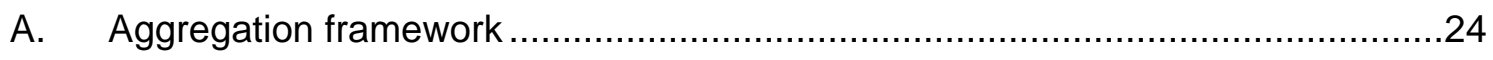

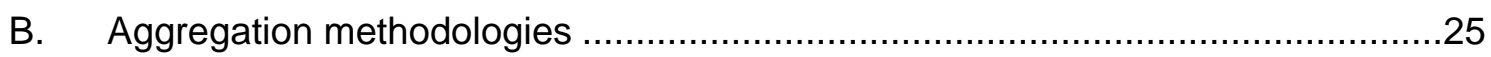

C. Range of practices in the choice of aggregation methodology ...........................30

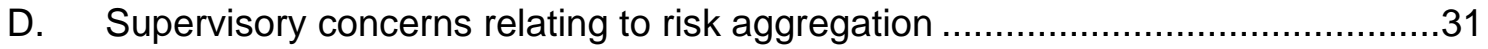

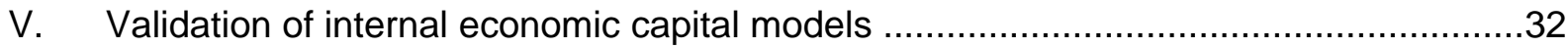

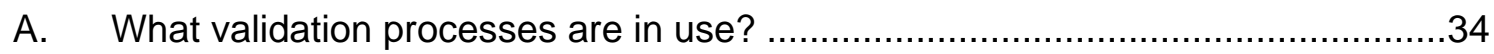

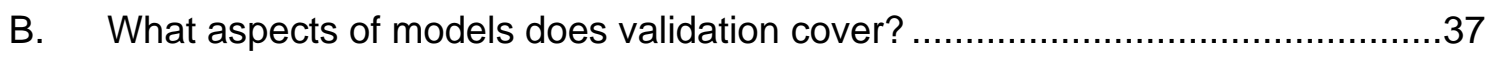

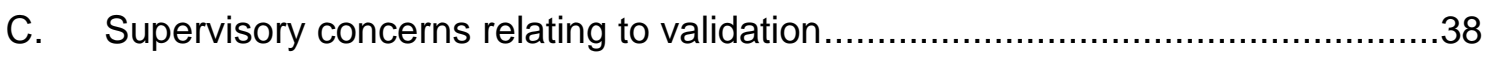

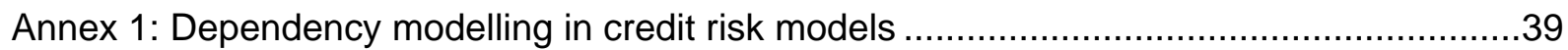

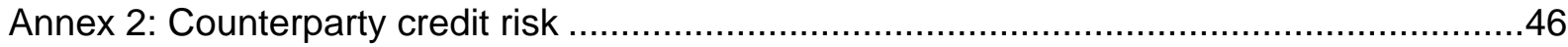

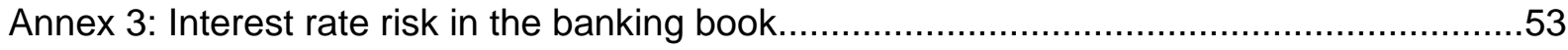

Annex 4: Members of the Risk Management and Modelling Group ..................................63 



\section{Executive Summary}

Economic capital can be defined as the methods or practices that allow banks to consistently assess risk and attribute capital to cover the economic effects of risk-taking activities. Economic capital was originally developed by banks as a tool for capital allocation and performance assessment. For these purposes, economic capital measures mostly need to reliably and accurately measure risks in a relative sense, with less importance attached to the measurement of the overall level of risk or capital. Over time, the use of economic capital has been extended to applications that require accuracy in estimation of the level of capital (or risk), such as the quantification of the absolute level of internal capital needed by a bank. This evolution in the use of economic capital has been driven by both internal capital management needs of banks and regulatory initiatives, and has been facilitated by advances in risk quantification methodologies and the supporting technological infrastructure.

While there has been some convergence in the understanding of key concepts of economic capital across banks with such frameworks in place, the notion of economic capital has broadened over time. This has occurred in terms of the underlying risks (or building blocks) that are combined into an overall economic capital framework and also in terms of the relative acceptance and use of economic capital across banks.

Economic capital can be analysed and used at various levels - ranging from firm-wide aggregation, to risk-type or business-line level, and down further still to the individual portfolio or exposure level. Many building blocks of economic capital, therefore, are complex and raise challenges for banks and supervisors. In particular, Pillar 2 (supervisory review process) of the Basel II Framework may involve an assessment of a banks' economic capital framework. Accordingly, this paper makes recommendations of particular interest to supervisors and bankers where economic capital models are used in the supervisory dialogue. In addition, supervisors have an interest in promoting robust, transparent and effective risk management, which in many cases requires an understanding of banks economic capital frameworks. Nevertheless, it is recognised that economic capital is a business tool developed and used by individual institutions for internal risk management purposes.

This paper emphasises the importance of understanding the relationship between overall economic capital and its building blocks, as well as ensuring that the underlying building blocks (individual risk assessments) are measured in a consistent and coherent fashion. The main body of the paper focuses on issues associated with the overall economic capital process, rather than on the component risks measured by economic capital. Therefore it covers issues related to the use and governance of economic capital, the choice of risk measures, aggregation of risk, and validation of economic capital. In addition, three important building blocks of economic capital (dependency modelling in credit risk, counterparty credit risk and interest rate risk in the banking book) are examined in separate, stand-alone annexes. This list of building blocks is chosen due to the significance and complexity of the topics, and (with the exception of counterparty credit risk) partly because the topics are not covered in Pillar 1 of the Basel II Framework. This list is by no means exhaustive.

\section{Use of economic capital and governance}

The robustness of economic capital and the governance and controls surrounding the process have become more critical as the use of economic capital has extended beyond 
relative risk measurement and performance to the determination of the adequacy of a bank's absolute level of capital.

The viability and usefulness of a bank's economic capital processes depend critically on the existence of a credible commitment or "buy-in" on the part of senior management to the process. In order for this to occur, it is necessary for senior management to recognise the importance of using economic capital measures in conducting the bank's business. In addition, adequate resources are required to ensure the existence of a strong, credible infrastructure to support the economic capital process. Economic capital model results should be transparent and taken seriously in order to be useful for business decisions and risk management. At the same time, management should fully understand the limitations of economic capital measures. Moreover, senior management needs to take measures to help ensure the meaningfulness and integrity of economic capital measures. It should also seek to ensure that the measures comprehensively capture all risks and implicit and/or explicit management actions embedded in measurement processes are both realistic and actionable.

\section{Risk measures}

Banks use a variety of risk measures for economic capital purposes with the choice of risk measure dependent on a number of factors. These include the properties of the risk measure, the risk- or product-type being measured, data availability, trade-offs between the complexity and usability of the measure, and the intended use of the risk measure. While there is general agreement on the desirable properties a risk measure should have, there is no singularly preferred risk measure for economic capital purposes. All risk measures observed in use have advantages and disadvantages which need to be understood within the context of their intended application.

\section{Risk aggregation}

One of the more challenging aspects of developing an economic capital framework relates to risk aggregation.

Practices and techniques in risk aggregation are generally less sophisticated than the methodologies that are used in measuring individual risk components. They rely heavily on ad-hoc solutions and judgment without always being theoretically consistent with the measurement of the components. Most banks rely on the summation of individual risk components either equally-weighted (ie assuming no diversification or a fixed percentage of diversification gains across all components) or weighted by an estimated variancecovariance matrix that represents the co-movement between risks. Few banks attempt technically more sophisticated aggregation methods such as copulas or even bottom-up approaches that build overall economic estimates from the common relationship of individual risk components to underlying factors.

Validation is a general problem with aggregation techniques. Diversification benefits embedded in inter-risk aggregation processes (including in the estimation of entries in the variance-covariance matrix) are often based on (internal or external) "expert judgment" or average industry benchmarks. These have not been (and very often cannot be) compared to the actual historical or expected future experience of a bank, due to lack of relevant data. 
Since individual risk components are typically estimated without much regard to the interactions between risks (eg between market and credit risk), the aggregation methodologies used may underestimate overall risk even if "no diversification" assumptions are used. Moreover, harmonisation of the measurement horizon is a difficult issue. For example, extending the shorter horizon applied to market risk to match the typically-used annual horizon of economic capital assessments for other types of risk is often performed by using a square root of time rule on the economic capital measure. This simplification can distort the calculation. Similar issues arise when risk measured at one confidence level is then scaled to become (nominally) comparable with other risk components measured at a different confidence level.

\section{Validation}

Economic capital models can be complex, embodying many component parts and it may not be immediately obvious that a complex model works satisfactorily. Moreover, a model may embody assumptions about relationships between variables or about their behaviour that may not hold in all circumstances (eg under periods of stress). Validation can provide a degree of confidence that the assumptions are appropriate, increasing the confidence of users (internal and external to the bank) in the outputs of the model. Additionally, validation can be also useful in identifying the limitations of economic capital models, ie where embedded assumptions do not fit reality.

The validation of economic capital models is at a very preliminary stage. There exists a wide range of validation techniques, each of which provides evidence for (or against) only some of the desirable properties of a model. Moreover, validation techniques are powerful in some areas such as risk sensitivity but not in other areas such as overall absolute accuracy or accuracy in the tail of the loss distribution. Used in combination, particularly in combination with good controls and governance, a range of validation techniques can provide more substantial evidence for or against the performance of the model. There appears to be scope for the industry to improve the validation practices that shed light on the overall calibration of models, particularly in cases where assessment of overall capital is an important application of the model.

\section{Dependency modelling in credit risk}

Portfolio credit risk models form a significant component of most economic capital frameworks. A particularly important and difficult aspect of portfolio credit risk modelling is the modelling of the dependency structure, including both linear relationships and non-linear relationships, between obligors. Dependency modelling is an important link between the Basel II risk weight function (with supervisory imposed correlations) and portfolio credit risk models which rely on internal bank modelling of dependencies. Understanding the way dependencies are modelled is important for supervisors when they examine a bank's internal capital adequacy assessment process (ICAAP) under Pillar 2, since these dependency structures are not captured in regulatory capital measures.

The underlying methodologies applied by banks in the area of dependency modelling in credit risk portfolios have not changed much over the past ten years. Rather, improvements have been made in the infrastructure supporting the methodologies (eg improved databases) and better integration with internal risk measurement and risk management. The main concern in this area of economic capital continues to centre on the accuracy and stability of 
correlation estimates, particularly during times of stress. The correlation estimates provided by current models still depend heavily on explicit or implicit model assumptions.

\section{Counterparty credit risk}

The measurement and management of counterparty credit risk creates unique challenges for banks. Measurement of counterparty credit risk represents a complex exercise, as it involves gathering data from multiple systems; measuring exposures from potentially millions of transactions (including an increasingly significant percentage that exhibit optionality) spanning variable time horizons ranging from overnight to thirty or more years; tracking collateral and netting arrangements; and categorising exposures across thousands of counterparties.

This complexity creates unique market-risk-related challenges (requiring calculations at the counterparty level and over multiple and extended holding periods) and credit risk-related challenges (estimation of credit risk parameters for which the institution may not have any other exposures). In addition, wrong-way risk, operational risk-related challenges, differences in treatment between margined and non-margined counterparties, and a range of aggregation challenges need to be overcome before a firm can have a bank-wide view of counterparty credit risk for economic capital purposes. Banks usually employ one of two general modelling approaches to quantify counterparty credit risk exposures, a Value at Risk (VaR)-type model or a Monte Carlo Simulation approach. The decision of which approach to use involves a variety of trade-offs. The VaR-type model cannot produce a profile of exposures over time, which is necessary for counterparties that are not subject to daily margining agreements, whereas the simulation approach uses a simplified risk factor representation and may therefore be less accurate. While these models may be supplemented with complementary measurement processes such as stress testing, such diagnostics are frequently not fully comprehensive of all counterparty credit risk exposures.

\section{Interest rate risk in the banking book}

The main challenges in the calculation of economic capital for interest rate risk in the banking book relate to the long holding period for balance sheet assets and liabilities and the need to model indeterminate cash flows on both the asset and liability side due to embedded optionality in many banking book items. If not adequately measured and managed, the asymmetrical payoff characteristics of instruments with embedded option features can present risks that are significantly greater than the risk measures suggest.

The two main techniques for assessing interest rate risk in the banking book are repricing schedules (gap and duration analyses) and simulation approaches. Although commonly used, the simple structure and restrictive assumptions make repricing schedules less suitable for the calculation of economic capital. Most banks use simulation approaches for determining their economic capital, based on losses that would occur given a set of worst case scenarios. The magnitude of such losses and their probability of occurrence determine the amount of economic capital. The choice of the techniques depends on the bank's preference towards either economic value or earnings, and also on the type of business. Some businesses, such as commercial lending or residential mortgage lending, are managed on a present value basis, while others such as credit cards are managed on an earnings basis. The use of an earnings based measure creates aggregation challenges 
when other risks are measured on the basis of economic capital. Conversely, the use of an economic value based approach may create inconsistencies with business practices.

\section{Summary}

Economic capital modelling and measurement practices continue to evolve. In some aspects, practices have converged and become more consistent over time, however the notion of economic capital has broadened as its use has expanded. There remain significant methodological, implementation and business challenges associated with the application of economic capital in banks, particularly if economic capital measures are to be used for internal assessments of capital adequacy. These challenges relate to the overall architecture of economic capital modelling and to the underlying building blocks. 


\section{Recommendations}

Economic capital models and the overall frameworks for their internal use can provide supervisors with information that is complementary to other assessments of bank risk and capital adequacy. While there is benefit from engaging with banks on the design and use of the models, supervisors should guard against placing undue reliance on the overall level of capital implied by the models in assessing capital adequacy. The following recommendations identify issues that should be considered by supervisors in order to make effective use of internal measures of risk that are not designed for regulatory purposes.

1. Use of economic capital models in assessing capital adequacy. A bank using an economic capital model in its dialogue with supervisors, should be able to demonstrate how the economic capital model has been integrated into the business decision making process in order to assess its potential impact on the incentives affecting the bank's strategic decisions about the mix and direction of inherent risks. The bank's board of directors should also be able to demonstrate conceptual awareness and understanding of the gap between gross (stand alone) and net enterprise wide (diversified) risk when they define and communicate measures of the bank's risk appetite on a net basis.

2. Senior management. The viability, usefulness, and ongoing refinement of a bank's economic capital processes depend critically on the existence of credible commitment or "buy-in" on the part of senior management to the process. In order for this to occur, senior management should recognise the importance of using economic capital measures in conducting the bank's business and capital planning, and should take measures to ensure the meaningfulness and integrity of economic capital measures. In addition, adequate resources should be committed to ensure the existence of a strong, credible infrastructure to support the economic capital process.

3. Transparency and integration into decision-making. A bank should effectively document and integrate economic capital models in a transparent way into decision making. Economic capital model results should be transparent and taken seriously in order to be useful to senior management for making business decisions and for risk management.

A bank should take a careful approach to its use of economic capital in internal assessments of capital adequacy. For this purpose, greater emphasis should be placed on achieving robust estimates of stand-alone risks on an absolute basis, as well as developing the flexible capacity for enterprise-wide stress testing.

4. Risk identification. Risk measurement begins with a robust, comprehensive and rigorous risk identification process. If relevant risk drivers, positions or exposures are not captured by the quantification engine for economic capital, there is great room for slippage between inherent risk and measured risk.

Not all risks can be directly quantified. Material risks that are difficult to quantify in an economic capital framework (eg funding liquidity risk or reputational risk) should be captured in some form of compensating controls (sensitivity analysis, stress testing, scenario analysis or similar risk control processes).

5. Risk measures. All risk measures observed in use have advantages and disadvantages which need to be understood within the context of their intended 
application. There is no singularly preferred risk measure for economic capital purposes. A bank should understand the limitations of the risk measures it uses, and the implications associated with its choice of risk measures.

6. Risk aggregation. A bank's aggregation methods should address the implications stemming from the definition and measurement of individual risk components. The accuracy of the aggregation process depends on the quality of the measurement of individual risk components, as well as on the interactions between risks embedded in the measurement process. Aggregation of individual risk components often requires the harmonisation of risk measurement parameters such as the confidence level or measurement horizon.

Care must be taken to ensure that the aggregation methodologies used (eg variance-covariance matrices, use of broad market proxies, and simple industry averages of correlations) are, to the extent possible, representative of the bank's business composition and risk profile.

7. Validation. Economic capital model validation should be conducted rigorously and comprehensively. Validation of economic capital models should be aimed at demonstrating that the model is fit for purpose. Evidence is likely to come from multiple techniques and tests. To the extent that a bank uses models to determine an overall level of economic capital, validation tools should demonstrate to a reasonable degree that the capital level generated by the model is sufficient to absorb losses over the chosen horizon up to the desired confidence level. The results of such validation work should be communicated to senior management to enhance economic capital model usage.

8. Dependency modelling in credit risk. Since the dependency structures embedded in portfolio credit risk models have an important impact on the determination of economic capital needs for credit risk, banks should carefully assess the extent to which the dependency structures they use are appropriate for their credit portfolio. Banks should identify and understand the main limitations of their credit portfolio models and their implementation. They should address those limitations by using adequate supplementary risk management approaches (eg sensitivity analysis, scenario analysis, timely review of parameters).

9. Counterparty credit risk. A bank should understand the trade-offs involved in choosing between the currently used methodologies for measuring counterparty credit risk. Complementary measurement processes such as stress testing should also be used, though it should be recognised that such approaches may still not fully cover all counterparty credit risk exposures. The measurement of counterparty credit risk is complex and entails unique market and credit risk related challenges. A range of aggregation challenges need to be overcome before a firm can have a bank-wide view of counterparty credit risk for economic capital purposes.

10. Interest rate risk in the banking book. Close attention should be paid to measuring and managing instruments with embedded option features, which if not adequately performed can present risks that are significantly greater than suggested by the risk measure. Trade-offs between using an earnings-based or economic value based approach to measuring interest rate risk in the banking book need to be recognised. The use of an earnings based measure creates aggregation challenges when other risks are measured on the basis of economic value. Conversely, the use of an economic value based approach may create inconsistencies with business practices. 


\section{Introduction ${ }^{1}$}

Economic capital, which can be defined as the methods or practices that allow financial institutions to consistently assess risk and to attribute capital to cover the economic effects of risk-taking activities, has increasingly become an accepted input into decision-making at various levels within banking organisations. Economic capital measures may be one of several key factors used to inform decision-making in areas such as profitability, pricing, and portfolio optimisation - particularly at the business-line level. Economic capital measures may also feed into senior management decisions relating to issues such as acquisitions and divestitures. Such measures are also used, primarily at the consolidated entity level, to assess overall capital adequacy. The increased use of economic capital by banks has been driven by rapid advances in risk quantification methodologies, greater complexity and sophistication of banks' portfolios, and supervisory expectations that banks must develop internal processes to assess capital adequacy, beyond regulatory capital adequacy guidelines that are not designed to fully reflect all the underlying material risks in a given bank's business activities.

Across banks there has been a narrowing in the range of definitions and treatment of the majority of risks that form the building blocks of economic capital models, particularly the risks that are more readily quantifiable. At the same time, however, the notion of economic capital is broadening in terms of the risks that it encompasses and the extent to which it is gaining acceptance across banks. That is, the inputs (or risks) that feed into the measurement of economic capital are subject to ongoing change and evolution.

Many banks appear to be sufficiently comfortable in using their economic capital framework in discussions with external stakeholders. Moreover, to varying degrees of granularity, banks have in recent years disclosed qualitative and quantitative aspects of their economic capital, including economic capital model descriptions, risk thresholds, methodologies for particular risks, use of economic capital, capital allocation by risk type and business units, and diversification estimates. ${ }^{2}$

Despite the advances that have been made by banks in developing their economic capital models, the further use and recognition of risk measures derived from these models remain subject to significant methodological, implementation and business challenges. These challenges stem from:

- $\quad$ the wide variety of applications of economic capital models (from business-line use to firm-wide decision-making to capital adequacy assessments);

- $\quad$ methodological challenges (particularly in the area of risk aggregation, coverage of risks, validation challenges, and risks that are not easily quantifiable);

- $\quad$ the ability of economic capital models to adequately reflect business-line operating practices and therefore provide appropriate incentives to business units;

- $\quad$ potential gaps in the coverage of risks (eg valuation risks in structured credit products);

1 This paper was prepared by the Basel Committee's Risk Management and Modelling Group (RMMG). The RMMG comprises risk management specialists and supervisors from member countries within and outside the Basel Committee. The list of members who contributed to this report is provided in Annex 4. The RMMG has developed its views based on information sourced from a wide range of presentations and documents provided by banks, supervisors and other industry participants.

2 See Samuel (2008). 
- $\quad$ the feasibility of any single risk measure to capture adequately all the complex aspects of banking risks; and

- $\quad$ the ability of economic capital models to be extended from being used as a common metric for relative risk measurement and performance to the determination of the adequacy of the absolute level of capital.

This paper provides an overview of the range of practices in economic capital modelling at large banking organisations, and based on this review discusses a range of issues and challenges surrounding economic capital models. The paper also discusses practices implemented by banks that attempt to address these challenges, and supervisory concerns relating to the current state of practice.

As economic capital has to varying degrees become a component of many banks' internal capital adequacy assessment processes (ICAAP), this paper is addressed to banks that have implemented or are considering implementing economic capital into their internal processes. The paper is also addressed to supervisors, who are required under Pillar 2 of the Basel II Framework, to review and evaluate banks' internal capital adequacy assessments.

The main body of this paper focuses on aspects of the overall architecture of economic capital models. In Section II the paper covers the use of economic capital models and the governance and control framework. Section III reviews the range of risk measures used by banks in their economic capital models. Section IV covers the range of practice in risk aggregation methods and section $\mathrm{V}$ discusses issues arising in the validation of economic capital models. The main body of the paper therefore focuses on issues that are at a level above that of individual risks. The paper does not discuss the estimation of important building blocks of economic capital models, such as the estimation of probability of default (PD), loss given default (LGD) and exposure at default (EAD) in credit risk models. This is not to say that estimation of these parameters is simple or without issues. Rather, these issues are outside the scope of this work and have been covered in detail in other publications. Nevertheless, the annexes to this document discuss three building blocks of economic capital models, namely dependency modelling in credit risk, counterparty credit risk and interest rate risk in the banking book. These topics are given closer attention in this paper due to a combination of their significance, inherent challenges and (with the exception of counterparty credit risk) partly because the topics are not covered in Pillar 1 (minimum capital requirements) of the Basel II Framework. Should the need arise, further work on other significant elements of economic capital may be undertaken in the future.

Finally, it is worth noting that this work was initiated well before the market turmoil that began in August 2007. This paper therefore examines general issues that are deemed to be relevant for economic capital modelling. It does not attempt to analyse or assess the performance of economic capital models during the market turmoil.

\section{Use of economic capital measures and governance}

In order to achieve a common measure across all risks and businesses, economic capital is often parameterised as an amount of capital that a bank needs to absorb unexpected losses over a certain time horizon at a given confidence level. Because expected losses are accounted for in the pricing of a bank's products and loan loss provisioning, it is only unexpected losses that require economic capital. Economic capital analysis typically involves an identification of the risks from certain activities or exposures, an attempt to measure and 
quantify those risks, the aggregation of those risks, and an attribution or allocation of capital to those risks.

Historically, banks have followed a path in their use of economic capital that begins with (i) business unit-level portfolio measurement and pricing profitability analysis followed by (ii) enterprise-wide relative performance measurement that migrates to capital budgeting/planning, acquisition/divestiture analysis, external reporting and internal capital adequacy assessment processes.

\section{A. Business-level use}

The effective use of economic capital at the business-unit level depends on how relevant the economic capital allocated to or absorbed by a business unit is with respect to the decision making processes that take place within it. Frequently, the success or failure of an economic capital framework in a bank can be assessed by looking at how business line managers perceive the constraints economic capital imposes and the opportunities it offers in the following areas: (i) credit portfolio management; (ii) risk-based pricing; (iii) customer profitability analysis, customer segmentation, and portfolio optimisation; and (iv) management incentives.

\section{Credit portfolio management}

Credit portfolio management refers to activities in which banks assess the risk/return profiles of credit portfolios and enhance their profitability through credit risk transfer transactions and/or control of the loan approval process. In credit portfolio management, the creditworthiness of each borrower is assessed in a portfolio setting. A loan with a higher stand-alone risk does not necessarily contribute more risk to the portfolio. A loan's marginal contribution to the portfolio, as a result, is critical to assessing the concentration of the portfolio. Economic capital is a measurement of the level of concentration. It is one of the factors used to determine which hedging facilities to employ in reducing concentration. According to the results presented in Rutter Associates LLC (2004), the use of credit portfolio management for reducing economic capital seems to be less dominant than for "management of concentrations" and for "protection against risk deterioration".

\section{Risk-based pricing}

The relevance of allocated economic capital for pricing certain products (especially traditional credit products) is widely recognised. In theory, under the assumption of competitive financial markets, prices are exogenous to banks, which act as price-takers and assess the expected return (ex ante) and/or performance (ex post) of deals by means of risk-adjusted performance measures, such as the risk-adjusted return on capital (RAROC). In practice, however, markets are segmented. For example, the market for loans can be viewed as composed of a wholesale segment, where banks tend to behave more as price-takers, and a commercial banking segment, where, due to well-known market imperfections (eg information asymmetries, monitoring costs, etc.), banks have a greater ability to set prices for their customers.

From an operational point of view, the difference is not so straightforward, as decisions on deals will be based on ex ante considerations with regard to expected RAROC in a pricetaking environment (leading to rejection of deals whose RAROC is below a given threshold) and on the proposal of a certain price (interest rate) to the customer in a price-setting environment. In both cases, decisions are driven by a floor (the minimum RAROC or 
minimum interest rate) computed according to the amount of economic capital allocated to the deal.

Risk-based pricing typically incorporates the variables of a value-based management approach. For example, the pricing of credit risk products will include the cost of funding (such as an internal transfer rate on funds), the expected loss (in order to cover loan loss allowances), the allocated economic capital, and extra-return (with respect to the cost of funding) as required by shareholders. Economic capital influences the credit process through the computation of a (minimum) interest rate considered to be adequate for increasing (or, at least, not decreasing) shareholders' value. Depending on the product and the internal rules governing the credit process, decisions regarding prices can sometimes be overridden. For example, this situation could occur because of consideration about the overall profitability of the specific customer relationship, or its desirability (eg due to reputational side-effects stemming from maintenance of the customer relationship, even when it proves to be no longer economically profitable). Generally, these exceptions to the rule are strictly monitored and require the decision be elevated to a higher level of management.

\section{Customer and product profitability analysis, customer segmentation and portfolio optimisation}

Regardless of the role played by the bank as a price-taker or a price-maker, the process cannot be considered complete until feedback has been provided to management about the final outcome of the decisions taken. The measurement of performance can be extended down to the customer level, through the analysis of customer profitability. Such an analysis aims at providing a broad and comprehensive view of all the costs, revenues and risks (and, consequently, economic capital absorption) generated by each single customer relationship.

While implementation of this kind of analysis involves complex issues related to the aggregation of risks at the customer level, its use is evident in identifying unprofitable or marginally profitable customers who attract resources that could be allocated more efficiently to more profitable relationships. This task is generally accomplished by segmenting customers in terms of ranges of (net) return per unit of risk. Provided the underlying inputs have been properly measured and allocated (not a simple task as it concerns risks and, even more, costs), this technique provides a straightforward indication of areas for intervention in assessing customer profitability.

By providing evidence on the relative risk-adjusted profitability of customer relationships (as well as products), economic capital can be used in optimising the risk-return trade-off in bank portfolios.

\section{Management incentives}

To become deeply engrained in internal decision-making processes, the use of economic capital needs to be extended in a way that directly affects the objective functions of decisionmakers at the business unit level. This is achieved by influencing the incentive structure for business-unit management. Anecdotal evidence suggests that incentives are the most sensitive element for the majority of bank managers, as well as being the issue that motivates their getting involved in the technical aspects of the economic capital allocation process. However, evidence suggests that compensation schemes rank quite low among the actual uses of economic capital measures at the business unit level. 


\section{B. Enterprise-wide or group-level use}

Economic capital provides banks with a common currency for measuring, monitoring, and controlling: (i) different risk types; and (ii) the risks of different business units. The risk types that are typically covered by banks' economic capital models are credit risk, market risk (including interest rate risk in the banking book - IRRBB) and operational risk. Concentration risk as an aspect of credit risk is also common. Other risks included are business/strategic risk, counterparty credit risk, insurance risk, real estate risk and model risk.

Quantitative approaches are generally applied to credit risk (including concentration and counterparty credit risk), market risk, interest rate risk in the banking book and operational risks. Strategic and reputational/legal risks are more likely to be assessed by nonquantitative approaches (with an exception being where reputational/legal risks are subsumed in operational risk). For these risks, no best practices have emerged so far within the industry. Challenges lie mainly in insufficient data and difficulties in modelling.

Some risks are viewed by banks as better covered by ensuring internal control procedures are in order to mitigate risk and/or prepare contingency funding plans (eg liquidity risk). Consequently, capital typically is not allocated for such risks.

\section{Relative performance measurement}

In order to assess relative performance on a risk-adjusted basis, banks calculate riskadjusted performance measures, where economic capital measures play an important role. The most commonly used risk-adjusted performance measures are risk-adjusted return on capital (RAROC) and shareholder value added (SVA). ${ }^{3}$ Many banks calculate these measures at various levels of the enterprise (eg entity level, large business unit level and portfolio level). The major difference between these two measures is that RAROC is a relative measure, while SVA is an absolute measure. RAROC provides information which is useful in comparing the performances of two portfolios with the same amount of economic net income, but with substantially different economic capital measures.

One of the key issues in using both RAROC and SVA for performance measurement is how to set the hurdle rate that reflects the bank's cost of capital. In this regard practices vary across banks. Some banks set a single cost of capital (eg weighted average cost of capital or target return on equity - ROE) across all business units, while other banks set required returns that vary according to the risks of the business units.

Some banks use lower confidence levels for performance assessment of business units than for their enterprise-wide capital adequacy assessment. This approach is based on the view that economic capital measures calculated at high confidence levels focus on extreme events and do not always provide appropriate information for senior management. Calculation of risk-adjusted performance measures at the large business unit levels (eg wholesale banking, trading) is more commonly observed than at the smaller business unit levels. In calculating economic net income, one of the challenges is how to allocate profits and costs to each unit, if more than one unit contributes a profit-generating transaction or benefits from a cost generating activity.

There are other risk-adjusted performance measures that could be used. Some of these measures include RORAC (return on risk-adjusted capital), ROCAR (return on capital at risk) and RAROA (risk-adjusted return on risk-adjusted assets). See Crouhy et al (2006). 
Banks use risk-adjusted performance measures in their performance assessment (eg comparing performance with a target, analysing historical performance) and compensation setting. Use of economic capital measures for risk-adjusted performance measures in a capital budgeting process is much more common practice than incorporating economic capital measures into the determination of compensation for business managers and staff.

\section{Capital budgeting, strategic planning, target setting and internal reporting}

Many banks allocate (hypothetical) capital to each business unit in their budgeting process, where economic capital measures play an important role. This process is also part of strategic planning (eg defining the bank's risk appetite) and target setting (eg profit, capital ratio or external rating). In order to facilitate business growth that improves risk-adjusted profitability, while operating within an overall risk appetite set by the board, many banks have established internal reporting/monitoring frameworks.

Generally, banks have a number of ways to conduct capital planning, most of which are not empirically-based, but instead are based on judgment and stress testing exercises. These include scenario analysis and sensitivity analysis, which introduce forward-looking elements into the capital planning process. That is, banks place more emphasis on qualitative rather than quantitative tools and expect to rely on management actions to deal with future events. It seems that banks take only a rough, judgmental approach to reviewing the performance and interaction of economic capital "demand" figures and available capital "supply" figures during times of stress. It does not appear that banks have a rigorous process for determining their capital buffers, although some banks systematically set their capital buffers at levels above regulatory minimums (about $120 \%-140 \%$ ). Banks' capital planning scenarios differ by chosen time horizon, with some choosing one year, and others choosing three to five years. Banks usually look at adverse events that would affect the bank individually or would affect markets more broadly (a pandemic is one scenario chosen by some banks for the latter). Some banks stress certain parameters in their economic capital models (eg they shock PDs based on a severe recession scenario) to assess the potential impact on economic capital.

\section{Acquisition/divestiture analysis}

In corporate development activities, such as mergers and acquisitions, some banks use the targets' economic capital measures as one of the factors in conducting due diligence. However, the number of banks using economic capital measures for corporate development activities is relatively smaller than the number of those using economic capital measures for the other purposes described above. According to the results of the IFRI and CRO Forum (2007) survey, only $25 \%$ of participating banks use economic capital measures for corporate development activities, such as mergers and acquisitions. On the other hand, it seems that this approach is more often used for mergers and acquisitions in emerging markets, where information on the targets' market values is far less readily available.

\section{External communication}

The major external communication channels where economic capital measures could be used include disclosure (eg annual reports, presentation materials for investors), dialogue with supervisory authorities and dialogue with rating agencies. Some banks disclose economic capital measures for each business unit and/or risk category and provide comparisons with allocated capital in their annual reports. Many more banks disclose this kind of information in other documents, such as presentation materials for investors. 


\section{Capital adequacy assessment}

Economic capital is a measure of risk, not of capital held. As such, it is distinct from familiar accounting and regulatory capital measures. Nevertheless, banks have extended the use of this enterprise-wide metric beyond performance measurement and strategic decision making to include an assessment of the adequacy of the institution's overall capitalisation. This practice is commonly observed at banks, including those whose economic capital implementation is in the earlier stages of development.

The comparison of an internal assessment of capital needs against capital available is part of banks' overall ICAAP. Large banks (which are likely to adopt internal ratings-based - IRB approaches under Basel II) tend to use an economic capital model for their ICAAP, whereas some smaller banks primarily use the minimum regulatory capital numbers for the ICAAP. Some of these banks adjust the Pillar 1 numbers (using multiples of the regulatory capital requirements, using different model parameters, looking at different confidence levels, etc.). Beyond risks that feature in regulatory capital computations, approaches are rather heterogeneous. Larger banks may use economic capital models for quantifiable risks while relying upon more subjective approaches for less quantifiable risks like reputational risk. Traditional economic capital methods are used in some cases to calculate risks beyond minimum regulatory capital requirements. In other cases, stress tests based on scenario analysis are used (eg for IRRBB).

\section{Governance}

The corporate governance and control framework surrounding economic capital processes is an important indicator of the reliability of economic capital measures used by banking institutions. Important parts of an effective economic capital framework include strong controls for making changes in risk measurement techniques, thorough documentation regarding risk measurement and allocation methodologies and assumptions, sound policies to ensure that economic capital practices adhere to expected procedures, and the meaningful application of economic capital measures to day-to-day business decision making. Moreover, the viability of a bank's economic capital processes depends critically on the existence of a credible commitment on the part of senior management to the process. In order for this to occur, however, senior management must recognise the importance of using economic capital measures in running the bank's business.

This section examines the current range of practices with regard to governance in the following areas: (i) senior management involvement and experience in the economic capital process; (ii) the unit involved in the economic capital process, eg risk management, strategy planning, treasury, etc. and its level of knowledge; (iii) the frequency of economic capital measurements; and (iv) policies, procedures, and approvals relating to economic capital model development, validation, on-going maintenance and ownership.

\section{Senior management involvement and experience in the economic capital process}

The most widely cited reasons for adopting an economic capital framework are to improve strategic planning, define risk appetite, improve capital adequacy, assess risk-adjusted business unit performance and set risk limits. For those institutions that have adopted or plan to adopt economic capital, the risk management team, senior management, supervisors and the board of directors were the most influential parties behind the decision. However, not all banks choose to adopt an economic capital framework, citing difficulties inherent in collecting and modelling data on infrequent and often unquantifiable risk at extremely high confidence levels. 
There are clear signs that acceptance of the role played by economic capital is increasingly embedded in the business culture of banks, driven both by industry progress and supervisory pressure. In addition, banks now seem to be broadly comfortable with the accuracy of the economic capital measures. This has resulted in increased use of economic capital in management applications and business decisions, as well as use in discussions with external stakeholders.

The barriers to the successful implementation of economic capital vary widely. However, according to the PricewaterhouseCoopers Survey (2005) only $14 \%$ of respondents cite lack of support from senior management as a barrier to successful implementation of an economic capital framework. ${ }^{4}$

\section{Unit involved in the economic capital process and its level of knowledge}

There is a wide range of organisational governance structures responsible for the economic capital framework at banking institutions. These governance structures range from involving highly concentrated responsibilities to involving highly decentralised responsibilities. For example, some banking institutions house a centralised economic capital unit within corporate Treasury, with formal responsibilities. However, components of the overall economic capital model or some parameters are outside the direct control of the economic capital owner. Other banks share responsibility for the economic capital framework between the risk function and the finance function, while others have a more decentralised structure, with responsibilities spread among a wider range of units. ${ }^{5}$

Once capital has been allocated, each business unit then manages its risk so that it does not exceed its allocated capital. In defining units to which capital is allocated, banks sometimes take into account their governance structure. For example, banks that delegate broader discretion to business unit heads tend to allocate capital to the business unit, leaving the business unit's internal capital allocation within the business line's control. On the other hand, management is likely to be more involved in the allocation of capital within business units if the bank's governance structure is more centralised. There seems to be divergence in the approach to this process. Some banks prefer rigid operation, where allocation units adhere to the original capital allocation throughout the budgeting period. On the other hand, other banks prefer a more flexible framework, allowing reallocation of capital during the budgeting period, sometimes with thresholds that trigger reallocation before consuming all the allocated capital.

\section{Frequency of economic capital measurements and disclosure}

Economic capital calculations have a strong manual component and data quality is a prominent concern. Hence, most banks calculate economic capital on a monthly or quarterly basis.

\footnotetext{
Among the other barriers selected by respondents, $64 \%$ cite difficulty of integrating economic capital within management decision-making; $62 \%$ cite difficulty in quantifying certain risk types; $59 \%$ cite problems with data integrity; $31 \%$ cite lack of incentives for specific business lines and product areas to co-operate; $23 \%$ cite lack of in-house expertise; and $23 \%$ cite uncertainty regarding supervisors attitudes toward economic capital.

5 According to the IFRI and CRO Forum (2007) survey, about $80 \%$ of the economic capital work is undertaken centrally, and about $20 \%$ by the business units. About $60 \%$ of the banks participating in the survey have economic capital functions that report directly to the Chief Risk Officer, while others have reporting lines to the Chief Financial Officer or the Corporate Treasury.
} 
Implementation of Basel II has fostered public disclosure of quantitative information on economic capital measures among banks. Although disclosure of quantitative economic capital measures is not mandatory under Pillar 3 (market discipline) of Basel II, the aim of Pillar 3 is to encourage market discipline by accurately conveying the actual financial condition of banks to the market. In addition to quantitative economic capital measures, qualitative information on the governance surrounding the economic capital framework of banks is becoming more important, since external market participants take into account the sophistication of the economic capital framework and bank management in their assessments of banks.

\section{Policies, procedures, and approvals relating to economic capital model development, validation, on-going maintenance and ownership}

Most banks have formalised policies and procedures for economic capital governance and analytics to ensure the consistent application of economic capital across the enterprise. For those banks that have adopted enterprise-wide policies and procedures, it is the responsibility of the business units to ensure that those policies and procedures are being followed. Some institutions that do not have formal policies and procedures have economic capital processes and analytics (eg coverage of off-balance sheet items, confidence level and holding period) that are inconsistent across organisational units.

Change-control processes for economic capital models are generally less formalised than for pricing or risk management models. They typically leverage off change-control processes of the underlying models and parameters. Changes to economic capital-specific methodologies (eg aggregation methodologies) are managed by the bank's economic capital owner, and may not be the same as the change control processes in other areas on the banking institution. Diagnostics procedures are typically run after an economic capital model change. Some banks require responsible parties to sign-off on any changes to methodology. However, formalised validation processes after changes, or internal escalation procedures in the event of unexpectedly large differences in the economic capital numbers, are uncommon.

Some banks specifically name an owner of the economic capital model. Typically, the owner provides oversight of the economic capital framework. However, few formal responsibilities are assigned the owner other than ensuring reports from all model areas are received in a timely manner and mechanically aggregating the individual components of the economic capital framework into a report.

\section{Supervisory concerns relating to use of economic capital and governance}

Senior management needs to ensure that there are robust controls and governance surrounding the entire economic capital process. There are several supervisory concerns relating to the use of economic capital measures and governance surrounding the economic capital framework.

\section{Standard for absolute versus relative measures of risk}

The robustness and conservativeness of economic capital as an estimate of risk becomes more important when a bank extends the use of measures designed initially as a common metric for relative risk measurement and performance to the determination of the adequacy of the absolute level of capital. Critical issues include: (i) comprehensive capture of the risks by the model; (ii) diversification assumptions; and (iii) assumptions about management actions. 
The types of risk that are included in economic capital models and the ICAAP vary across banks in a given country as well as across countries (partly because some risk types are more pronounced in some countries). Risks that the economic capital model cannot easily measure may be considered as a separate judgmental adjustment in the ICAAP. Whether a risk type is included in the ICAAP may depend on the risk profile of the individual bank, and whether the individual bank regards these risks as material.

There can be variation between banks in the risks covered by their economic capital models, since an identically named risk type may be defined differently across banks and across countries. The term business risk, for example, is sometimes confused with or lumped together with less quantifiable legal and reputational risk.

In most cases, intra-risk diversification assumptions are built into the models for individual risk types. For inter-risk diversification assumptions, current practices vary among banks and the banking industry does not seem to have agreed on best practices. Thus, the methods remain preliminary and require further analysis. In light of the uncertainty in estimating diversification effects, especially for inter-risk diversification, due consideration for conservatism may be important. The issue of inter-risk diversification is addressed in detail in section IV, and intra-risk diversification (within portfolio credit risk modelling) is discussed in Annex I.

In some banks, potential management actions are taken into account in economic capital models. However, one of the main reasons that banks do not include management actions in their economic capital models is that these actions are difficult to model. Even if management actions are not explicitly included in economic capital models due to unreliability, banks would nevertheless prepare for them via contingency plans in stress situations.

Potential management actions are grouped into two categories: (i) those actions that increase capital supply; and (ii) those actions that reduce capital demand. Examples of the former are raising new capital, reducing costs and cutting dividends. Examples of the latter include reducing new investment or selling assets with positive risk weights. In addition to explicit actions, actions may be implicitly accounted for in the economic capital model itself. In measuring market risk, for example, some assumptions may be made to adjust the short time horizon in the model to the typically longer time horizon used in an economic capital framework.

Finally, banks do not seem to take into account constraints that could impede the effective implementation of management actions. Such constraints may relate to legal issues, reputational effects, and cross-border operations. Further analysis of the range and plausibility of these built-in assumptions about management action, particularly in times of stress, may be warranted.

\section{Role of stress testing}

Currently, many banks apply stress tests, including scenario analysis and sensitivity analysis, to individual risks, although the framework and procedures still need to be improved. The use of integrated stress tests is gradually becoming more widespread in the industry, probably reflecting the need to assess the impact of stress events on overall economic capital 
measures and to provide complementary estimates of capital needs in the context of ICAAP. At present, there exists wide variation among banks in the level and extent of integrated stress tests being utilised. In general however, practices are still in the development stage.

Stress test results do not necessarily lead to additional capital. Rather, it seems more common that stress tests are used to confirm the validity of economic capital measures, to provide complementary estimates of capital needs, to consider contingency planning and management actions, and gradually to formulate capital planning. In some cases, banks use stress tests to determine the effects of stressed market conditions on earnings rather than on economic capital measures.

\section{Economic capital should not be the sole determinant of required capital}

In general, both rating agencies and shareholders influence the level of a bank's capital, with the former stressing higher capital for solvency and the latter lower capital for profitability. Banks also look to peers in targeting their capital ratios. Nearly all large, internationally active banks set their economic capital solvency standard at a level they perceive to be required to maintain a specific external rating (eg AA). Banks tend to look to peers in choosing external ratings and associated solvency standards. There is not a lot of evidence that bank counterparties have an impact on capital levels, other than indirectly through the need to deal with institutions having an acceptably high external rating. Many banks claim to target a high external rating because of their desire to access capital and derivatives markets.

\section{Definition of available capital}

There is no common definition of available capital across banks, either within a country or across countries. Some of the confusion surrounding the notion of available capital may arise from the fact that economic capital has its origin in assessing relative profitability for the shareholder on a risk-adjusted basis. To the extent that a bank recognises its capital needs are not limited by the more quantifiable risks in its economic capital model, the broader it may choose to define available capital.

While no common definition of available capital exists, there are several elements that many banks have in common with regard to their available capital. At the root of many banks' definitions of available capital are tangible equity, tier one capital or capital definitions used by rating agencies. In order to cover losses at higher levels of confidence, some banks consider capital instruments that may be loss-absorbing, more innovative or uncertain forms of capital such as subordinated debt. Among the various items that can be included in the definition of available capital (some of them included in the regulatory definition of capital) are common equity, preferred shares, adjusted common equity, perpetual non-cumulative preference shares, retained earning, intangible assets (eg goodwill), surplus provisions, reserves, contributed surplus, current net profit, planned earning, unrealised profits and mortgage servicing rights.

This range of practices is confirmed by the IFRI and CRO Forum (2007) survey of enterprisewide risk management at banks and insurance companies, which found $80 \%$ of participants adjusted their tier 1 capital in arriving at available capital resources against which economic capital was compared.

Banks do not limit themselves to a single capital measure. Some banks manage their capital structure against external demands, such as regulatory capital requirements or credit rating agency expectations. Often banks' definition of capital aligns with the more tangible capital measures such as those used by rating agencies and are, therefore, more restrictive than regulatory definitions of capital. 


\section{Senior management commitment to the economic capital process}

The viability and usefulness of a bank's economic capital processes depend critically on the existence of credible commitment or "buy-in" on the part of senior management to the process. In order for this to occur, senior management must recognise the importance of using economic capital measures in conducting the bank's business and capital planning. In addition, adequate resources must be committed to ensure the existence of a strong, credible infrastructure to support the economic capital process.

\section{Transparency and meaningfulness of economic capital measures}

Economic capital model results need to be transparent and taken seriously in order to be useful to senior management for making business decisions and for risk management. The level of documentation and integrity of calculations and model version control increase with the scope and significance of economic capital models in a bank's decision making process. Internal transparency is a necessary condition for internal acceptance and use.

\section{Risk measures}

While risk is a notion with a clear intuitive meaning, it is less clear how risk should be quantified. Current practice in banks commonly involves trying to identify ways to characterise entire loss distributions (ie going beyond estimating selected moments of the loss distribution, such as the mean and standard deviation), resulting in a wide range of potential risk measures that may be used. The choice of risk measure has important implications for the assessment of risk. For example, the choice of risk measure could have an impact on the relative risk levels of asset classes and thus on the bank's strategy. Comparisons between ICAAP measures of capital under Pillar 2 with minimum regulatory capital requirements under Pillar 1 should consider the impact of using different measures of risk in the two approaches.

\section{A. Desirable characteristics of risk measures}

An ideal risk measure should be intuitive, stable, easy to compute, easy to understand, coherent and interpretable in economic terms. Additionally, risk decomposition based on the risk measure should be simple and meaningful.

Intuitive: The risk measure should meaningfully align with some intuitive notion of risk, such as unexpected losses.

Stable: Small changes in model parameters should not produce large changes in the estimated loss distribution and the risk measure. Similarly, another run of a simulation model in order to generate a loss distribution should not produce a dramatic change in the risk measure. Also, it is desirable for the risk measure not to be overly sensitive to modest changes in underlying model assumptions.

Easy to compute: The calculation of the risk measure should be as easy as possible. In particular, the selection of more complex risk measures should be supported by evidence that the incremental gain in accuracy outweighs the cost of the additional complexity.

Easy to understand: The risk measure should be easily understood by the bank's senior management. There should be a link to other well-known risk measures that influence the risk management of a bank. If not understood by senior management, the risk measure will 
most likely not have much impact on daily risk management and business decisions, which would limit its appropriateness.

Coherent: The risk measure should be coherent and satisfy the conditions of: (i) monotonicity (if a portfolio $Y$ is always worth at least as much as $X$ in all scenarios, then $Y$ cannot be riskier than $X$ ); (ii) positive homogeneity (if all exposures in a portfolio are multiplied by the same factor, the risk measure also multiplies by that factor); (iii) translation invariance (if a fixed, risk-free asset is added to a portfolio, the risk measure decreases to reflect the reduction in risk); and (iv) subadditivity (the risk measure of two portfolios, if combined, is always smaller or equal to the sum of the risk measures of the two individual portfolios). Of particular interest is the last property, which ensures that a risk measure appropriately accounts for diversification. ${ }^{6}$

Simple and meaningful risk decomposition (risk contributions or capital allocation): In order to be useful for daily risk management, the risk measured for the entire portfolio must be able to be decomposed to smaller units (eg business lines or individual exposures). If the loss distribution incorporates diversification effects, these effects should be meaningfully distributed to the individual business lines.

\section{B. Types of risk measures}

In practical applications, a wide range of risk measures are used. This section examines standard deviation, Value at Risk (VaR), expected shortfall (ES), and spectral and distorted risk measures. ${ }^{7}$ All the risk measures have strengths and weaknesses, since no single measure can capture all the complex elements of risk measurement. As such, there is no ideal risk measure. Table 1 presents (with some degree of subjective judgement) the characteristics of the main types of risk measures:

See Artzner et al (1997) on coherent risk measures for a complete discussion.

7 See Hull (2007) for a detailed discussion of the various risk measures. 
Table 1: Risk Measures

\begin{tabular}{|c|c|c|c|c|}
\hline & $\begin{array}{l}\text { Standard } \\
\text { Deviation }\end{array}$ & VaR & $\begin{array}{l}\text { Expected } \\
\text { Shortfall }\end{array}$ & $\begin{array}{l}\text { Spectral and } \\
\text { Distorted Risk } \\
\text { Measures }\end{array}$ \\
\hline Intuitive & $\begin{array}{l}\text { Sufficiently } \\
\text { intuitive }\end{array}$ & Yes & $\begin{array}{l}\text { Sufficiently } \\
\text { intuitive }\end{array}$ & $\begin{array}{l}\text { No (involves choice } \\
\text { of spectrum or } \\
\text { distortion function) }\end{array}$ \\
\hline Stable & $\begin{array}{l}\text { No, depends on } \\
\text { assumptions } \\
\text { about loss } \\
\text { distribution }\end{array}$ & $\begin{array}{l}\text { No, depends on } \\
\text { assumptions } \\
\text { about loss } \\
\text { distribution }\end{array}$ & $\begin{array}{l}\text { Depends on the } \\
\text { loss distribution }\end{array}$ & $\begin{array}{l}\text { Depends on the } \\
\text { loss distribution }\end{array}$ \\
\hline $\begin{array}{l}\text { Easy to } \\
\text { compute }\end{array}$ & Yes & $\begin{array}{l}\text { Sufficiently easy } \\
\text { (requires estimate } \\
\text { of loss distribution) }\end{array}$ & $\begin{array}{l}\text { Sufficiently easy } \\
\text { (requires estimate } \\
\text { of loss distribution) }\end{array}$ & $\begin{array}{l}\text { Sufficiently easy } \\
\text { (weighting of loss } \\
\text { distribution by } \\
\text { spectrum/distortion } \\
\text { function) }\end{array}$ \\
\hline $\begin{array}{l}\text { Easy to } \\
\text { understand }\end{array}$ & Yes & Yes & Sufficiently & $\begin{array}{l}\text { Not immediately } \\
\text { understandable }\end{array}$ \\
\hline Coherent & $\begin{array}{l}\text { Violates } \\
\text { monotonicity }\end{array}$ & $\begin{array}{l}\text { Violates } \\
\text { subadditivity (for } \\
\text { non-elliptical loss } \\
\text { distributions) }\end{array}$ & Yes & Yes \\
\hline $\begin{array}{l}\text { Simple and } \\
\text { meaningful risk } \\
\text { decomposition }\end{array}$ & $\begin{array}{l}\text { Simple, but not } \\
\text { very meaningful }\end{array}$ & $\begin{array}{l}\text { Not simple, might } \\
\text { induce distorted } \\
\text { choices }\end{array}$ & $\begin{array}{l}\text { Relatively simple } \\
\text { and meaningful }\end{array}$ & $\begin{array}{l}\text { Relatively simple } \\
\text { and meaningful }\end{array}$ \\
\hline
\end{tabular}

In practice, VaR and ES are the two most widely used risk measures. While VaR is more easily explained and understood, it may not always satisfy the subadditivity condition and this (lack of coherence) can cause problems in banks' internal capital allocation and limit setting for sub-portfolios. ${ }^{8} \mathrm{ES}$, on the other hand, is coherent, making capital allocation and internal limit setting consistent with the overall portfolio measure of risk. However, ES does not lend itself to easy interpretation and does not afford a clear link to a bank's desired target rating. A newer class of risk measures, known as spectral and distorted risk measures, allow for different weights to be assigned to the quantiles of a loss distribution, rather than assuming equal weights for all observations, as is the case for ES. ${ }^{9}$

8 VaR is subadditive for elliptical distributions, such as the Gaussian (or normal) distribution, whereas it is not subadditive for non-elliptical distributions. The non-subadditivity of VaR can occur when assets in portfolios have very skewed loss distributions; when the loss distributions of assets are smooth and symmetric, but their dependency structure or copula is highly asymmetric; and when underlying risk factors are independent but very heavy-tailed. The lack of subadditivity for $\mathrm{VaR}$ is probably more of a concern for credit risk and operational risk than for market risk, where an elliptical model may be a reasonable approximate model for various kinds of risk-factor data. For a detailed discussion, see McNeil et al (2005). Many practitioners note however, that the technical reservations concerning $\mathrm{VaR}$ are mainly academic in nature and that the problems described are encountered by banks only rarely in practice.

9 Spectral and distorted risk measures are not widely used in practice and are currently largely of academic interest . 
Banks typically use several of the aforementioned risk measures, and sometimes different measures for different purposes. However, $\mathrm{VaR}$ is the most widely used risk measure. Some banks use VaR for measuring the absolute risk level, but increasingly ES is used (at a confidence level consistent with overall VaR) for capital allocation within the bank. The argument is often made that $\mathrm{VaR}$ as an absolute risk measure or loss limit is still easier to communicate to senior management due to its link to a bank's target rating. On the other hand, ES is a more stable measure than VaR with respect to allocating the overall portfolio capital to individual facilities. ES is a loss measure estimate given a loss range in the tail of the loss distribution, while VaR is a loss measure estimated given a particular point in the tail of the loss distribution. It should be noted that, while a bank may use different risk measures, these measures are typically based on the same estimated loss distribution.

\section{Calculation of risk measures}

\section{Confidence level}

In their internal use of risk measures, banks need to determine an appropriate confidence level for their economic capital models that may vary for different business models. The banks' target rating plays an important role in the choice of confidence level.

The link between a bank's target rating and the choice of confidence level may be interpreted as the amount of economic capital that must be exceeded by available capital resources to prevent the bank from eroding its capital buffer at a given confidence level. According to this view, which can be interpreted as a going concern view, capital planning is seen more as a dynamic exercise than a static one, where it is the probability of eroding such a buffer (rather than all available capital) that is linked to the target rating. This would reflect the expectation (by analysts, rating agencies and the market) that the bank operates with capital that exceeds the regulatory minimum requirement.

Establishing the link between a bank's target rating and the choice of confidence level, however, is far from being an easy exercise. It involves the mapping between ratings and PDs, which can change, depending on the rating agency scale adopted, and it suffers from significant statistical noise, especially at the higher rating grades which are typically targeted by banks. Banks can use a range of confidence levels for the same target rating, with overlaps between different rating classes. For example, the IFRI and CRO Forum (2007) survey found that PDs mapped to a AA target rating, range from two to seven basis points, while the range for an $A$ target rating is four to ten basis points.

Apart from considerations about the link to a target rating, the choice of a confidence level might differ based on the question to be addressed. On the one hand, high confidence levels reflect the perspective of creditors, rating agencies and supervisors in that they are used to determine the amount of capital required to minimise bankruptcy risk. On the other hand, banks may use lower confidence levels for management purposes in order to allocate capital to business lines and/or individual exposures and to identify those exposures that are critical for profit objectives in a normal business environment. Consequently, banks typically use different confidence levels for different purposes.

Another interesting aspect of the internal use of different risk measures is that the choice of risk measure and confidence level heavily influences relative capital allocations to individual exposures or portfolios. In short, the farther out in the tail of a loss distribution, the more relative capital gets allocated to concentrated exposures. As such, the choice of the risk measure as well as the confidence level can have a strategic impact since some portfolios might look relatively better or worse under risk-adjusted performance measures than they would based on an alternative risk measure. 


\section{Time horizon}

All risk measures depend on the time horizon used in their measurement. The choice of an appropriate time horizon depends on a range of factors: the liquidity of the bank's assets under consideration; the risk management needs of the bank, the bank's standing in the markets; the risk type, etc. Market risk is typically estimated over a very short time horizon (days or weeks). In contrast, credit risk is typically measured using a one-year time horizon, while an even longer time horizon may be appropriate for other portfolios (eg project finance). The choice of time horizon is also influenced by regulatory requirements. For example, a one-year time horizon is specified for operational risk, while a 10-day time horizon is specified for general and specific market risk.

The heterogeneity of time horizons used in risk measurement poses an important challenge to banks in aggregating economic capital across different risk types. According to the IFRI and CRO Forum (2007) survey about $80 \%$ of participants use a time horizon of one year for their economic capital calculations, with the remainder using various time horizons.

\section{Aggregation/decomposition}

Measurement of risk is typically performed at the portfolio level. However the ability to easily and sensibly aggregate and decompose risks is an important feature of any risk measure.

In order to be effectively used, risk measures should be flexible and able to be computed at either a broad or narrow level. More specifically:

- $\quad$ Decomposition: Within a portfolio, risk needs to be decomposed in order to establish for each subset (eg positions assigned to each desk) its risk contribution (taking into account any diversification effects). Decomposition of risk is fundamental for capital allocation, limit setting, pricing of products, risk-adjusted performance measurement and value-based management.

- $\quad$ Aggregation: Adopting a wider point of view, risks arising from several portfolios need to be aggregated in order to convey a representation of risk at the business unit or entity level. Aggregation also deals with different types of risk (credit, market, operational, liquidity, legal, etc.). Typically, the outcome of risk aggregation is the bank's total economic capital.

\section{Supervisory concerns relating to risk measures}

From a supervisory point of view, there is no obvious preference for one risk measure over another among the measures most widely used for calculating economic capital. Rather, supervisors should consider the advantages and disadvantages of the risk measure used at each bank. Stability in computation is an important issue, as the calculation of risk measures typically involves the use of simulation techniques. The ability to easily and sensibly aggregate and decompose risk also determines the effective use of risk measures in the bank. The degree to which economic capital is engrained in the decision-making processes is strongly affected by the availability of a broad assessment of risks at the senior management level, where strategic decisions are made with respect to capital management. In contrast, more granular measures of risk are needed at the risk-taking levels where economic capital is likely to influence operational decisions through factors such as capital allocation, limit setting, and performance measurement.

While each bank chooses both the risk measure and the confidence level it deems most appropriate for its economic capital purposes, the bank must be able to provide a convincing economic rationale for the choice. If different risk measures and/or confidence levels are 
used for external and internal management purposes, a clear and convincing link must be established between the two risk measures.

Supervisors should be aware of differences between internal and regulatory measures of capital that stem from different risk measures and/or confidence levels and take these into account when evaluating a banks' ICAAP. A simple comparison of internal and regulatory capital figures will not tell supervisors much about the underlying risks in a bank's portfolio.

\section{Risk aggregation}

Typically, economic capital is calculated using an approach that first assesses individual risk components, and then proceeds to aggregate these components up to the level of the entire bank. The aggregation process is characterised by identification of the individual risk types and by the methodological choices made in aggregating these risk types.

\section{A. Aggregation framework}

Risk aggregation begins with a classification of risk types that are combined to produce the overall economic capital measure. Banks typically classify risk into different types along two dimensions: (i) the economic nature of the risk (market risk, credit risk, operational risk, etc.); and (ii) the organisational structure of the bank (along business lines or legal entities).

In contrast to classification along organisational lines, which presents few conceptual difficulties, classification along risk types can be imprecise. Definitions of risk types may differ across institutions, or even across portfolios within a single banking organisation, often reflecting the nature of the bank's business or the degree of sophistication of its risk measurement. As discussed below, this imprecision has implications for the aggregation process.

The following list provides a brief description of the main categories into which the typical framework classifies risks.

Market risk: Refers to portfolio value changes due to changes in rates and prices that are perceived as exogenous from the viewpoint of the bank. These comprise exposures to asset classes such as equities, commodities, foreign exchange and fixed-income, as well as to changes in discount factors such as the risk-free yield curve and risk premiums. A specific type of market risk is IRRBB, which stems from repricing risk (arising from differences in the maturity and repricing terms of customer loans and liabilities), yield curve risk (stemming from asymmetric movements in rates along the yield curve), and basis risk (arising from imperfect correlation in the adjustment of the rates earned and paid on different financial instruments with otherwise similar repricing characteristics). IRRBB also arises from the embedded option features of many financial instruments on banks' balance sheets.

Credit risk: Refers to portfolio value changes due to shifts in the likelihood that an obligor (or counterparty) may fail to deliver cash flows (principal and interest) as previously contracted. The distinction between market and credit risk, while fairly clear on the surface, is less so in practice since individual exposures typically contain elements of both risks. For example, prices of corporate bonds can vary because of changes in the perceived likelihood of issuer default but also because shifts in the risk-free yield curve. In addition, credit and market risk factors can interact in ways that complicate the distinction between the two (see the next section). 
Operational risk: Refers to the risk of loss associated with human or system failures, as well as fraud, natural disaster and litigation. While not a pure economic risk it does represent losses (either outright outlays or foregone earnings) from all types of activity where banks engage, and it is indirectly linked to the level, intensity and complexity of these activities.

Business risk: Captures the risk to the firm's future earnings, dividend distributions and equity price. In leading practice banks, business risk is more clearly defined as the risk that volumes may decline or margins may shrink, with no opportunity to offset the revenue declines with a reduction in costs. For example, business risk measures the risk that a business may lose value because its customers sharply curtail their activities during a market down-turn or because a new entrant takes market share away from the bank. Moreover, this risk increasingly extends beyond balance-sheet items to fee-generating services, such as origination, cash management, asset management, securities underwriting and client advisory services.

For business or (local) regulatory reasons, some banks may select to distinguish individual types of risk within the listed categories. For example, they may isolate real estate risk, or pension risk. Some banks may also distinguish other risk types such as liquidity risk and legal risk.

\section{Range of practices in the choice of risk types}

All the risk types discussed above can be simultaneously present in a bank's portfolio. For example, a traded bond portfolio will have an important credit and market risk component, as well as operational risk related to the efficiency of trading execution and settlement. In practice, however, risks are often measured by reference to different lines of business and/or portfolios. A loan portfolio that is held to maturity and managed on an accrual accounting basis is often considered as representing credit risk and not market risk. By contrast, a trading portfolio of credit derivatives is often taken to represent mainly market risk by virtue of it containing actively traded exposures that are marked-to-market.

The majority of banks prefer to aggregate risk initially into silos by risk-type across the entire bank before combining the silos. This approach, however, is by no means the only approach followed, with the business unit silo approach preferred by other banks. Some banks use a mixed approach, which combines elements of both approaches. This practice is observed where either particular business units or risk exposures are too small to be meaningfully measured separately.

Grouping of risks first across homogeneous risk types has a benefit of addressing these questions at a single stage and in a centralised and potentially more consistent way. By comparison, grouping risks first by business unit leverages the existing organisational structures within the bank and deals with inter-risk relationships at an earlier stage of aggregation.

\section{B. Aggregation methodologies}

The risk aggregation methodology used by a bank has two (interrelated) components: the choice of the unit of account and the approach taken to combining risk components.

\section{The unit of account}

Before risk types are aggregated into a single measure, they need to be expressed in comparable units, often referred to as a common risk currency. Meaningful aggregation 
requires that the underlying risk measures conform to each other, especially when they relate to single number summaries of the corresponding risk distributions. There are three main characteristics of the unit of risk accounting.

Risk metric: The choice of the risk metric for economic capital depends on the metrics that are used in the quantification of different risk components. In particular, whether the chosen metric satisfies the subadditivity property is relevant for quantifying diversification across risk types. ${ }^{10}$

Confidence level: The fact that the loss distribution for different risk types are typically assumed to have different shapes (ie different families of probability distributions are assumed to better capture the characteristics of different types of risk) may also suggest a difference in terms of the relevant confidence levels. For example, long-tailed risk distributions would suggest using higher confidence levels. Lack of harmonisation in terms of the choice of confidence level creates additional complexity in aggregation approaches. ${ }^{11}$ Moreover, the choice of confidence level can influence the ranking of risks since risk types that have a loss distribution with a longer loss tail tend to dominate as the confidence level increases.

Time horizon: The choice of the horizon over which risk is measured is one of the thorniest issues in risk aggregation. Business practice, accounting standards and regulatory requirements combine to imply that different types of risk are managed over different horizons. Traded portfolios are managed over horizons that are typically measured in days. Less liquid exposures, such as loans, are managed over longer horizons of one year or longer. ${ }^{12}$ Combining risk measures that have been calculated on the basis of different horizons is problematic regardless of the specific methodology used. The conflict between business practices and risk aggregation requirements is typically resolved by using a common (usually one year) horizon. This means that it is necessary for time aggregation of certain types of risk (most often market risk) by using scaling-up methods such as the square-root-of-time rule. It should be noted that there is no conceptual inconsistency in the use of different horizons for risk measurement and EC purposes, on the one hand, and for the actual management of underlying exposures, on the other. Decisions related to the management of portfolios are based on the characteristics of the exposures (including their liquidity) and on the purpose for which they are held. However, for the purpose of risk measurement and, especially, risk aggregation the use of different horizons will result in improper comparisons between risk components. The difficulty that arises for the latter purposes can be overcome by methods similar to the constant level of risk over a common horizon approach outlined in the consultative paper of the BCBS on computing incremental risk in the trading book. ${ }^{13}$

\section{Inter-risk diversification}

The way that individual risks are combined relates closely to the scope of inter-risk diversification, namely to the notion that the combination of two portfolios would result in

10 See the section on risk measures for a more detailed discussion of the properties of different metrics of risk.

11 More sophisticated methods that use full simulation approaches or those that describe the entire loss distribution (such as those based on copulas) would not be influenced by this choice.

12 Even with the same time horizon for default, the practice of active credit portfolio management can result in the use of point-in-time default probabilities for day-to-day risk management with through-the-cycle estimates for economic capital computations.

13 Basel Committee on Banking Supervision (2009) 
lower risk per unit of investment in the combined portfolio than the (weighted) average of the two component portfolios. The basic intuition stems from the fact that the variance of the pooled portfolio's return will be no greater (and typically smaller) than a similarly sized portfolio which is exposed to only one or the other risk factor. This logic will carry over to measures of risk that are directly related to variance.

In the context of risk aggregation across different portfolios or business units, some of the assumptions that underpin the above logic may fail to hold. One issue is purely technical and relates to the choice of $\mathrm{VaR}$ as a metric because it can fail to satisfy the subadditivity property. That is, it is possible for the VaR of a pooled portfolio to be higher than the sum of the VaR of the individual constituent portfolios.

A more important reason why aggregate risk may be larger than the sum of its components is independent of the choice of metric (ie it applies to metrics other than VaR) and relates to the economic underpinnings of the portfolios that are pooled. The logic outlined above assumes that covariance (a linear measure of dependence) fully captures and summarises the dependencies across risks. While this may be a reasonable approximation in many cases, there are instances where the risk interactions are such that the resulting combination may represent higher, not lower, risk. For example, measuring separately the market and credit risk components in a portfolio of foreign currency denominated loans can underestimate risk, since probabilities of obligor default will also be affected by fluctuation in the exchange rate, giving rise to a compounding effect. ${ }^{14}$ Similar types of "wrong-way" interactions could occur in the context of portfolio positions that may be simultaneously affected by directional market moves and the failure of counterparties to a hedging position. ${ }^{15}$ From a more "macro" perspective, asset price volatility often interacts with the risk appetite of market participants and feeds back to market liquidity leading to a magnification of risk rather than diversification.

A final issue that relates to the degree of diversification has to do with the granularity of the classification system of risks. The more granular the classification system (ie the finer the system of categories where risk is slotted) the more reduced should be the scope for intrarisk diversification and the higher the scope for inter-risk diversification. For example, holding everything else equal, some of the overall diversification between the retail and wholesale credit portfolio of a bank will be subsumed in the measure of overall credit risk for a bank that does not distinguish between the two types of risks in its economic capital framework, while it will be picked up by the aggregation process in the case that the bank maintains a separation between the two components until the final aggregation stage.

\section{Typically used aggregation methodologies}

Banks differ in their choice of methodology for the aggregation of economic capital. The list below provides an overview of the main approaches followed by a brief discussion of their advantages and disadvantages. The approaches are listed in increasing order of complexity (decreasing order of restrictiveness).

(i) Simple summation: This simple approach involves adding the individual risk components. Typically, this is perceived as a conservative approach since it ignores potential

14 See Breuer et al (2008) for further details. The forthcoming working paper on the "Interactions between market and credit risk" produced by the Research Task Force of the Basel Committee also offers an elaboration on this set of issues

15 See Annex 2 on counterparty credit risk for a fuller discussion. 
diversification benefits and produces an upper bound to the true economic capital figure. Technically, it is equivalent to assuming that all inter-risk correlations are equal to one and that each risk component receives equal weight in the summation.

(ii) Applying a fixed diversification percentage: This approach is essentially the same as the simple summation approach with the only difference that it assumes the sum delivers a fixed level of diversification benefits, set at some pre-specified level of overall risk.

(iii) Aggregation on the basis of a risk variance-covariance matrix: The approach allows for a richer pattern of interactions across risk types. However, these interactions are still assumed to be linear and fixed over time. The overall diversification benefit depends on the size of the pairwise correlations between risks.

(iv) Copulas: This is a much more flexible approach to combining individual risks than the use of a covariance matrix. The copula is a function that combines marginal probability distributions into a joint probability distribution. The choice of the functional form for the copula has a material effect on the shape of the joint distribution and can allow for rich interactions between risks.

(v) Full modelling of common risk drivers across all portfolios: This represents the theoretically pure approach. Common underlying drivers of risk are identified and their interactions modelled. Simulation of the common drivers (or scenario analysis) provides the basis for calculating the distribution of outcomes and economic capital risk measure. Applied literally, this method would produce an overall risk measure in a single step since it would account for all risk interdependencies and effects for the entire bank. A less comprehensive approach would use estimated sensitivities of risk types to a large set of underlying fundamental risk factors and construct the joint distribution of outcomes by tracking the effect of simulating these factors across all portfolios and business units. 
Table 2: Comparison of risk aggregation methodologies

\begin{tabular}{|c|c|c|}
\hline Aggregation methodology & Advantages & Disadvantages \\
\hline \multirow[t]{2}{*}{$\begin{array}{l}\text { Summation: } \\
\text { Adds together individual capital } \\
\text { components }\end{array}$} & \multirow[t]{2}{*}{$\begin{array}{l}\text { Simplicity } \\
\text { Typically considered to be } \\
\text { conservative }\end{array}$} & $\begin{array}{l}\text { It does not discriminate across } \\
\text { risk types; imposes equal } \\
\text { weighting assumption }\end{array}$ \\
\hline & & $\begin{array}{l}\text { Does not capture non- } \\
\text { linearities }\end{array}$ \\
\hline \multirow[t]{2}{*}{$\begin{array}{l}\text { Constant diversification: } \\
\text { Similar to summation but } \\
\text { subtracts fixed percentage from } \\
\text { overall figure }\end{array}$} & \multirow[t]{2}{*}{$\begin{array}{l}\text { Simplicity and recognition of } \\
\text { diversification effects }\end{array}$} & $\begin{array}{l}\text { The fixed diversification effect } \\
\text { is not sensitive to underlying } \\
\text { interactions between } \\
\text { components. }\end{array}$ \\
\hline & & $\begin{array}{l}\text { Does not capture non- } \\
\text { linearities }\end{array}$ \\
\hline \multirow{2}{*}{$\begin{array}{l}\text { Variance-Covariance: } \\
\text { Weighted sum of components } \\
\text { on basis of bilateral correlation } \\
\text { between risks. }\end{array}$} & $\begin{array}{l}\text { Better approximation of } \\
\text { analytical method }\end{array}$ & $\begin{array}{l}\text { Estimates of inter-risk } \\
\text { correlations difficult to obtain }\end{array}$ \\
\hline & Relatively simple and intuitive & $\begin{array}{l}\text { Does not capture non- } \\
\text { linearities }\end{array}$ \\
\hline \multirow{2}{*}{$\begin{array}{l}\text { Copulas: combine marginal } \\
\text { distributions through copula } \\
\text { functions }\end{array}$} & $\begin{array}{l}\text { More flexible than covariance } \\
\text { matrix }\end{array}$ & $\begin{array}{l}\text { Parameterisation very difficult } \\
\text { to validate }\end{array}$ \\
\hline & $\begin{array}{l}\text { Allows for nonlinearities and } \\
\text { higher order dependencies }\end{array}$ & $\begin{array}{l}\text { Building a joint distribution very } \\
\text { difficult }\end{array}$ \\
\hline \multirow{3}{*}{$\begin{array}{l}\text { Full modelling/Simulation: } \\
\text { Simulate the impact of common } \\
\text { risk drivers on all risk } \\
\text { components and construct the } \\
\text { joint distribution of losses }\end{array}$} & $\begin{array}{l}\text { Theoretically the most } \\
\text { appealing method }\end{array}$ & $\begin{array}{l}\text { Practically the most demanding } \\
\text { in terms of inputs }\end{array}$ \\
\hline & $\begin{array}{l}\text { Potentially the most accurate } \\
\text { method }\end{array}$ & Very high demands on IT \\
\hline & Intuitive & $\begin{array}{l}\text { Can provide false sense of } \\
\text { accuracy }\end{array}$ \\
\hline
\end{tabular}

Table 2 provides a summary of the trade-offs between numerical accuracy, methodological consistency, intuitive appeal, practicality, flexibility, and resource implications associated with each of the aggregation methodologies.

Although the most restrictive of the alternative methodologies, the main advantages of the summation and fixed diversification methodologies are simplicity in terms of data and computational requirements, and ease of communication about the method and interpretation of the outcome. Abstracting from the possibility of mis-measurement and negative correlation between the underlying risk components, the simple summation approach could also produce a conservative measure of overall risk (ie overstatement of risk). The degree of conservatism associated with the fixed diversification method depends on the chosen diversification parameter. Both methods are relatively crude and do not allow for meaningful interactions between risk types or for differences in the way these risk types may create diversification benefits. In addition, both methods ignore complications stemming from using different confidence levels in measuring individual risk components.

The use of a variance-covariance matrix (or correlation matrix) which summarises the interdependencies across risk types provides a more flexible framework for recognising diversification benefits, while still maintaining the desirable features of being intuitive and easy to communicate. The correlation matrix between risks is of key importance. This matrix can vary across banks reflecting differences in their business mix, and the correlations that 
reflect these institution-specific characteristics can be difficult as well as costly to estimate and validate. This is particularly true for operational risk, where data are scarce and do not cover long time periods. In addition, by focusing on average covariance between risks, the linearity assumption will tend to underestimate dependence in the tail of loss distributions and underestimate the effects of skewed distributions and non-linear dependencies.

Copulas offer even greater flexibility in the aggregation of risks and promise a better approximation of the true risk distribution. This comes at the expense of more demanding input requirements: complete distributions of the individual risk components rather than simple summary statistics (such as $\mathrm{VaR}$ ) and at least as much data as the variancecovariance approach for estimating the copula parameters. As for the variance-covariance method, these estimates are hard to derive and to validate. Many of the same drawbacks apply to the case of full models of economic capital, including full simulation methods. The input requirements in terms of data on exposures and underlying risk factor dynamics, as well as the computational demands associated with large scale simulations represent a strain for most banks, especially those banks with more complex business risk profiles.

\section{Range of practices in the choice of aggregation methodology}

Currently, there is no established set of best practices concerning risk aggregation in the industry. Generally the chosen approaches tend to be towards the simpler end of the spectrum, with very few (typically large) banks using the more sophisticated methodologies. The vast majority of banks use some form of the summation approach, where risks are either explicitly weighted, as in the case of the variance-covariance approach, or implicitly weighted (as in the case of simple aggregation). The IFRI and CRO Forum (2007) survey suggests that more than $60 \%$ of banks use the variance-covariance approach while less than $20 \%$ use the simulation approaches. Reportedly, the stability of the latter approach over time is an attractive aspect from a governance perspective, since it leads to a more stable allocation of diversification benefits back to individual business units.

Banks use a variety of approaches in setting values for the inter-risk variance-covariance matrix. These approaches include direct estimation using historical time series on underlying risks, expert judgment, and industry benchmarks (frequently supplied by consulting firms). The estimation based on internal data is arguably more appropriate since it reflects the actual experience of the bank and is more directly applicable to its business and risk profile. As suggested above, the interactions between risk components can be complex, non-linear, time varying, and dependent on measurement choices. If the bank possesses relevant data of sufficient quality and length, these data should provide the most appropriate indicators of inter-risk dependencies. These data can be related to the performance of portfolios (P\&L, earnings, loss history, etc.). Often risks that present greater quantification challenges need to be approximated by banks with less well developed IT systems. In these cases, the correlation between risk components is in practice often approximated by the co-movement of asset price indices representative of these risk factors, or similar proxies.

Very often bank-specific data are simply not available or of poor quality. In this case the entries in the variance-covariance matrix are filled on the basis of expert judgment, in the form of parameters that reflect the consensus of risk officers and business managers within the firm, and this is frequently complemented with input from external consultants and industry benchmarks. This is particularly true when it applies to some risk components such as operational risk or business risk. The reliance on externally supplied inputs may be a necessity for medium and small-sized institutions that lack the capacity, scope and scale economies to develop risk correlation measures based on their own experience. The same applies to proportionately small exposures in the case of larger institutions. 
There is a tendency for banks to use what they consider as a "conservative" variancecovariance matrix. The correlations are often reported to be approximate (eg rounded up to multiples of 25 percentage points) and biased upwards (ie. towards unity). In an effort to reduce the need for expert judgment banks might consciously limit the dimensionality of the matrix by consolidating risk categories to a small number, not recognising that such consolidation itself represents a form of aggregation and embeds correlation assumptions. One drawback of this practice is that each category becomes less homogeneous and thus harder to quantify. In light of uncertainties for estimating inter-risk diversification effects as well as the possibility that correlations may be time-varying, some (but not all) banks use stressed values that refer to the periods when these correlations may be higher than they are on average, or even set equal to unity. ${ }^{16}$ Even in those cases where average values are used, banks report that they examine the effect on the calculated economic capital from using such stressed correlations as a robustness check. Generally, there is a tendency for banks with less sophisticated economic capital methodologies to follow a principle of conservatism in their approaches.

Whatever the method and the estimates used, there are a number of commonalities in the assumptions made by banks. For instance, a high correlation between market and credit risks is usually assumed, a lower correlation between business risk and credit or market risk, and a very low correlation between operational risk and all other risks.

Related to the calibration of the covariance matrix of risks is the overall level of diversification across risk types. According to the IFRI and CRO Forum (2007) survey, the estimated range of inter-risk diversification is $10 \%$ to $30 \%$ for banking organisations (with $40 \%$ of banks reporting gains between $15 \%$ and $20 \%$ ). This range depends on the method used by banks in order to take into account inter risk diversification and the varying estimates of correlation between risk types. Academic studies on this issue indicate that this range can vary very substantially depending on the applied methodology and the data used. Rosenberg and Schuermann (2006) estimate this diversification at more than $40 \%$ at the $99.9 \%$ confidence level but underscore that this might vary depending on the specific portfolio composition. Dimakos and Aas (2004) on the other hand find only 10\%-12\% diversification at confidence intervals of $95 \%$ to $99 \%$, but a number closer to $20 \%$ at confidence interval of $99.97 \%$.

\section{Supervisory concerns relating to risk aggregation}

An important overall message is that meaningful aggregation of risk necessarily involves compromises and judgment to augment quantitative methods. Risk measurement in portfolios that are more homogeneous in terms of their risk drivers can be quite detailed and can address different facets of risk. The combination of different types of risk into a common metric, however, presents many more complications stemming either from the different statistical profiles of risk types or from differences in the perspective and requirements of the business units that manage different portfolios (eg the use of different metrics and/or management horizons). Aggregation, therefore, typically requires that some of the richness of assessments made on the individual components is sacrificed in order to achieve comparability.

In particular, supervisory concerns with the economic capital aggregation relate to validation of the inputs, methodology, and outputs of the process.

16 Using stressed correlations is also justified on the basis that, in periods of stress, available capital resources might be less "fungible" across risks/business units as implicitly assumed in the aggregation of its uses. 
Economic capital frameworks are very difficult to validate. Economic capital refers to holistic measures of risk in often very diverse business environments. Moreover, the more tailored the process to the character and needs of the individual bank, the more difficult for an external observer to independently validate the inputs. Additionally, the short history of available data renders backtesting impracticable in most cases. Many supervisors report that validation processes typically do not meet their expectations. In particular, many supervisors are sceptical as to the validity of the size of diversification benefit estimates and do not accept them for supervisory use.

As mentioned above, the degree of diversification is linked to the measurement methodology of individual components. From an applied point of view the potential complications with risk measurement are primarily related to the common practice of identifying risk categories with individual portfolios. For a number of practical reasons that have to do with the way banks manage different types of risk, with financial reporting practices, and with the regulatory framework, different types of risk are often identified with single portfolios. For example, market risk is thought of being primarily associated with portfolios that are held with the intention of active trading, are managed on a short risk horizon, and are often marked-tomarket. Credit risk is associated mainly with the banking book which contains exposures with a longer holding horizon, that they are often illiquid and valued on an accrual basis. This simplistic distinction can give rise to mistaken assessments of market and credit risk components that can bias the aggregation process. ${ }^{17}$ The main message from the supervisory perspective is that diversification cannot be taken as given irrespective of the portfolio of risks and risk measurement practices. There is a theoretical possibility that risk components may be mis-measured and that aggregate risk may be higher than the sum of the risk components. This may be the exception rather than the rule, but the fact remains that mis-measurement can often lead to under-estimation of overall risk.

Finally a possible drawback of the more sophisticated methodologies is more of a behavioural nature. Often greater methodological sophistication leads to greater confidence in the accuracy of the outcomes. Given the diversity in the nature of inputs, the importance of assumptions that underline the parameters used, and the scale of the task in practical applications, the scope for hard-to detect and quantify inaccuracies is considerable. Complex approaches that are not accompanied by robustness checks and estimates of possible specification and measurement error can prove misleading.

\section{Validation of internal economic capital models}

In some cases the term validation is used exclusively to refer to statistical ex post validation, while in other cases it is seen as a broader but still quantitative process that also incorporates evidence from the model development stage. In this paper, the term "validation" is used in a broad sense, meaning all the processes that provide evidence-based assessment about a model's fitness for purpose. This assessment might extend to the management and systems environment within which the model is operated. Moreover, it is advisable that validation processes are designed alongside development of the models, rather than chronologically following the model building process.

17 A working paper of the Basel Committee's Working Group on the Interaction of Market and Credit Risk contains a more in-depth discussion of these issues and references to relevant papers. 
Validation provides evidence that a model works as planned. Economic capital models can be complex, embodying a lot of moving parts and it may not be immediately obvious that a complex model works satisfactorily. Moreover, a model may embody assumptions about relationships between variables or about their behaviour under periods of stress. Validation can permit a degree of confidence that the assumptions are appropriate, increasing the confidence of users (internal and external to the bank) in the outputs of the model. Notably, validation also aids in identifying model limitations, since no model (even when fully validated) is ever a perfect representation of reality. While validation can provide powerful tools for the assessment of many aspects of models, such as its risk sensitivity, it is less powerful where other aspects of models are concerned, such as confirming the accuracy of high quantiles in a loss distribution.

Achieving an accurate fit may not always be the prime consideration. For example, some models may be developed because of their usefulness as a framework for analysis or decision-making rather than because of their ability to fit historical data. Some macroeconomic models of economic behaviour may fall into this category.

Our interpretation of validation is consistent with that developed by the Basel Committee (2005a) in relation to the Basel II Framework, which is phrased in terms of the IRB parameters ${ }^{18}$ and was developed in the context of assessment of risk estimates for use in minimum capital requirements. However, validation of economic capital models differs to the validation of an IRB model as the output is a distribution rather than a single predicted forecast against which actual outcomes may be compared. Economic capital models are conceptually similar to VaR models, though the long time horizon, high confidence levels, and the scarcity of data force validation methods to differ in practice to those used for VaR. Full internal economic capital models are not used for Pillar 1 minimum capital requirements, and so fitness for purpose needs to cover a range of uses, most of which and perhaps all are internal to the firm in question. It should also be noted that economic capital models and regulatory capital serve different objectives and so may reasonably differ in some of the details of their implementation for these differing purposes.

Principle 1 of the Basel Committee's validation principles refers to assessment of the predictive ability of credit rating systems. ${ }^{19}$ The emphasis is on the performance of forecasts generated by the model. As it stands, Principle 1 is about rating systems: the natural development of this principle for economic capital models is that validation is concerned with the predictive properties of those models. Economic capital models embody forward-looking estimates of risk and their validation is intimately bound up with assessing those estimates and so this (re-stated) principle remains appropriate. The validation processes as set out in this paper are, in their different ways, all providing insight into the likely predictive ability of the model, interpreted broadly.

The other Basel II principles related to validation principles are: the bank has primary responsibility for validation; validation is an iterative process, there is no single method, validations should encompass both quantitative and qualitative elements; and validation processes and outcomes should be subject to independent review. The notion of validation expressed in this paper is consistent with these principles. Our discussion of validation does

18 From the 2005 Validation principles: "In the context of rating systems, the term 'validation' encompasses a range of processes and activities that contribute to an assessment of whether ratings adequately differentiate risk, and whether estimates of risk components (such as PD, LGD or EAD) appropriately characterise the relevant aspects of risk."

19 Principle 1 reads: "Validation is fundamentally about assessing the predictive ability of a bank's risk estimates and the use of ratings in credit processes". 
not address, however, the question of who needs to perform the model assessment or which party needs to be satisfied by that model assessment.

\section{A. What validation processes are in use?}

Most of this section describes the types of validation processes that are in use or could be used. The list is not comprehensive, and it is not suggested that all techniques should be used by banks. Other surveys that provide fuller descriptions of techniques are available. ${ }^{20}$ Our purpose is to make two points. First, to demonstrate that there is a wide range of techniques that would be covered by our broad definition of validation, creating a layered approach. The more layers that can be provided, the more comfort that validation is able to provide evidence for or against the performance of the model. Conversely, where fewer layers of validation are used, the level of comfort diminishes. Second, that each validation process provides evidence for (or against) only some of the desirable properties of a model. The list presented below moves from the more qualitative to the more quantitative validation processes, and the extent of use is briefly discussed.

\section{Qualitative processes}

(i) Use test. The philosophy of the use test has been fully incorporated into the Basel II Framework. Its relevance as a tool of validation is straightforward. If a bank is actually using its risk measurement systems for internal purposes, then supervisors can place more reliance on the systems' outputs for regulatory capital. Applying the use test successfully will entail gaining a careful understanding of which model properties are being used and which are not. ${ }^{21}$

(ii) Qualitative review. Banks tend to subject their models to some form of qualitative assessment process. This process could entail review of documentation, review of development work, dialogue with model developers, review and derivation of any formulae, comparison with what other firms are known to do, comparison with publicly available information. Qualitative review is best able to answer questions such as: Does the model work in theory? Does it incorporate the right risk drivers? Is any theory underpinning it conceptually well-founded? Is the mathematics of the model right?

(iii) Systems implementation. Production-level risk measurement systems should go through extensive testing prior to implementation, such as user acceptance testing, checking of model code etc. These processes could be viewed as part of the overall validation effort, since they would assist in evaluating whether the model is implemented with integrity.

(iv) Management oversight. Management oversight refers to the involvement of senior management in the validation process, in reviewing output from the model, and using the results in business decisions. Senior management need to be clear how the model is used and how the model outputs are interpreted, taking account of the specific implementation

20 See BCBS (2005b)

21 Paragraph 4 of the Basel Committee's validation principles sets out some of the uses of capital models. In discussing the use test for IRB, the paper notes "... as a quality check of IRB components and underlying processes, the use test is a necessary supplement to the overall validation process. ... the use test plays a key role in ensuring and encouraging the accuracy, robustness and timeliness of a bank's IRB components, confirms the bank's trust in those components and allows supervisors to place more reliance on their robustness and thus on the adequacy of regulatory capital." We think that this philosophy still holds true when considering internal capital models. 
framework that their firm has adopted and the assumptions underlying the model and its parameterisation.

(v) Data quality checks. Not traditionally viewed by the industry as a form of validation but increasingly forming a major part of regulatory thinking. Data quality checks refers to the processes designed to provide assurance of the completeness, accuracy and appropriateness of data used to develop, validate and operate the model. These processes could include qualitative review (eg of data collection and storage), data cleaning processes such as identifying errors, reviews of the extent of proxy data, review of any processes that need to be followed to convert raw data into suitable model inputs (eg scaling processes), and verification of transaction data such as exposure levels. Such a list is often a helpful indication of the level of understanding of the model.

(vi) Examination of assumptions - sensitivity testing. Models rest on assumptions of various kinds, some of which are obvious, but some are less so. As such, certain aspects of models are 'built-in' and cannot be altered without changing the model. To illustrate, these assumptions could be: assumptions about fixed model parameters such as correlations or recovery rates; assumptions about the shape of tail distributions; and assumptions about the behaviour of senior management or of customers. Some banks go through a deliberate process of detailing the assumptions underpinning their models. This should include examination of the impact on model outputs, and the limitations that the assumptions place on model usage and applicability.

\section{Quantitative processes}

(i) Validation of inputs and parameters. Some model parameters may be estimated. Examples include the main IRB parameters and correlation parameters. A complete model validation would involve validation of the inputs themselves. Validation of input parameters to economic capital models would entail validation of those parameters not included in IRB, such as correlations. Techniques could include checking model parameters against historical data, comparison of parameters against outcomes over time, comparison of model parameters to market-implied parameters such as implied volatility or implied correlation, and assessing materiality of model output to input and parameters through sensitivity testing. Testing of input parameters would be a complement to the examination of assumptions and sensitivity testing described in the preceding paragraph.

It is worth noting that checking of model inputs is unlikely to be fully satisfactory since every model is based on underlying assumptions. The richer or more sophisticated the model, the more susceptible it may be to model error. Checking of input parameters will not shed light on this area. However, model accuracy and appropriateness can be assessed, at least to some degree, using the processes described in this section.

(ii) Model replication. A useful quantitative technique is to try to replicate the model results obtained by the bank. A truly independent replication would use independently developed algorithms and an alternative source of data but in practice replication might be done by leveraging some of the bank's processes. For example, it could be done by running the bank's algorithms on a different data set or using the bank's own databases with independently derived algorithms, once the banks' processes have been validated and are reliable. This technique (and the questions that often arise in attempting to replicate results) can help to identify whether or not the definitions and the algorithms that the bank says it is using are correctly understood by staff in the bank who develop, maintain, operate and validate the model and that they are used in practice by the bank. The technique also facilitates code checking and may be helpful in determining whether the databases analysed in the validation process are those used by the bank to obtain its results. This technique is rarely sufficient to validate models and in practice there is little evidence of it being used by 
banks for either validation or to explore the degree of accuracy of their models. Note that replication simply by re-running a set of algorithms to produce an identical set of results would not be sufficient model validation due diligence.

(iii) Benchmarking and hypothetical portfolio testing. This refers to the examination of whether the model produces results comparable to a standard reference model or comparing models on a set of reference portfolios. Examples of benchmarking could include comparison of risk ranking provided by internal rating systems and agency ratings, or comparison of an in-house portfolio credit model to other well-known models after standardisation of parameters. In the regulatory field, this permits comparison of several banks' models against the same reference model. It would allow identification of models that produce outliers. Hypothetical portfolio testing means comparison of models against the same reference portfolio. It is capable of addressing similar questions to benchmarking by different means. The technique is a powerful one and can be adapted to analyse many of the preferred model properties such as rank-ordering and relative risk quantification. But there are also limitations. In particular, benchmarking can only compare one model against another and may provide little assurance that the model accurately reflects reality or about the absolute levels of model output. In a benchmarking exercise, there may be good reasons why models produce outliers. They may, for example, be designed to perform well under differing circumstances, or may be conservatively parameterised, or may differ in their economic foundations, all of which complicate interpretation of the results.

Benchmarking is a commonly used form of quantitative validation. Comparisons are made with industry survey results, against alternative models such as a rating agency model, industry-wide models, consultancy firms, academic papers and regulatory capital models. However, as a validation technique, benchmarking has limitations, providing comparison of one model against another or one calibration to others, but not testing against 'reality'. It is therefore difficult to assess the degree of comfort provided by such benchmarking methods, as they may only be capable of providing broad comparisons confirming that input parameters or model outputs are broadly comparable.

(iv) Backtesting. Backtesting addresses the question of how well the model forecasts the distribution of outcomes. Backtesting may take many forms and there is a wide literature on the subject. All backtesting approaches entail some degree of comparison of outcomes to forecasts, and there is a wide literature on the subject.

For portfolio credit models, the weak power of backtesting is noted in BCBS (1999). As has been suggested by some authors, there are variations to the basic backtesting approach which can increase the power of the tests. Examples include: performing backtesting more frequently over shorter holding periods (eg using a one-day market risk backtesting standard versus the 10-day regulatory capital standard); using cross-sectional data by backtesting on a range of reference portfolios; ${ }^{22}$ using information in forecasts of the full distribution; ${ }^{23}$ testing expected losses only; and comparing outcomes against the expected values of distributions as opposed to high quantiles.

Backtesting is useful principally for models whose outputs can be characterised by a quantifiable metric with which to compare an outcome. There may be risk measurement systems in use whose outputs cannot be interpreted in this way. Examples could include rating systems, sensitivity tests and aggregated stress losses. Such risk measurement

\footnotetext{
22 See Lopez and Saidenberg (1999).

23 See Frerichs and Löffler (2002) and Berkowitz (2000).
} 
approaches might nevertheless be valuable tools for banks. The role of backtesting for such models, if they were to be used, would need elaboration.

In practice, backtesting is not yet a key component of banks' validation practices for economic capital purposes.

(v) Profit and loss attribution. Analysis of profit and loss on a regular basis (eg annually) and comparison between causes of actual profit and loss and the risk drivers in the model. Attribution is not widely used except for market risk pricing models.

(vi) Stress testing. This covers both stressing of the model and comparison of model outputs to stress losses.

The outputs of the model might be examined under conditions of stress, where model inputs and model assumptions might be stressed. This process can reveal model limitations or highlight capital constraints that might only become apparent under stress. Stress testing of regulatory capital models, particularly IRB models, is undertaken by banks but there is more limited evidence of stress testing of economic capital models.

Through a complementary programme of stress testing, the bank may be able to quantify the likely losses that the firm would confront under a range of stress events. Comparison of stress losses against model-based capital estimates may provide a modest degree of comfort of the absolute level of capital. Banks report some use of this stress testing technique to validate the approximate level of model output.

Internal audit is not included in the above list, however validation of the overall implementation framework and process should also be subject to independent and periodic review and this work should be made by parties within the banking organisation that are independent of those accountable for the design and implementation of the validation process. One possibility could be that internal audit would be in charge of undertaking this review process. As such it could be viewed as comprising a part of the management oversight process listed above. The paper does not otherwise discuss the role of internal audit in the validation process.

The list of validation tools does not address the issue of adequate standards. Banks may operate internal standards that are relevant for validation. For example, a description of the issues that need to be addressed as part of validation, the standards that capital models are expected to achieve, a series of quantitative thresholds that models need to meet, warning indicators for particular monitoring metrics, assessment against model development standards.

\section{B. What aspects of models does validation cover?}

The validation steps presented above can be used in assessing most of the desirable properties of models. This is an encouraging observation and stands in contrast to the fairly negative view of validation taken in BCBS (1999).

Opinions may reasonably differ about the strength or weakness of any particular process in respect of any given property. The properties that could be assessed using a powerful tool and hence that are capable of robust assessment include: integrity of implementation; grounded in historical experience; risk sensitivity; sensitivity to the external environment; good marginal properties; rank ordering; and relative quantification. The properties for which only weaker processes are available include: conceptual soundness; forward-looking; and absolute risk quantification. Again, it is important to stress the judgemental evaluation of the 
power of individual tests and to acknowledge that views as to strength and weakness are likely to differ.

The difficulty of validating the conceptual soundness of a capital model needs some elaboration. In developing a model, several assumptions about the model and its inputs are likely to be made. These could include assumptions about the family of statistical distributions, the economic processes driving default or loss, the dependency structure among defaults or losses, the likely behaviour of management or other economic agents, and the extent to which these vary over time. Moreover, some internal capital models are risk aggregation models, where risk estimates for individual categories (eg market, credit and operational risk) are aggregated to generate a single total economic capital figure, with the method of aggregation relying on some underpinning assumptions. These assumptions, however, may be untestable. As a result it may be impossible to be certain that a model is conceptually sound. While the conceptual underpinnings may appear coherent and plausible, they may in practice be no more than untested hypotheses.

This section presented the main validation tools available with which to assess internal capital models and provided some evaluation of their power and their use in practice. The conclusion is that tools are powerful in some areas such as risk sensitivity but not in other areas such as overall absolute accuracy.

\section{Supervisory concerns relating to validation}

Compared to practice at the time of the BCBS (1999) report, there is greater emphasis currently on the validation of models. The main areas of improvement are in benchmarking of model parameters and the conduct of cross-firm comparisons of models, typified by the IACPM and ISDA study (2006) on portfolio credit risk models. There is some evidence that banks wish to ensure that models are sensitive to the expected drivers of risk, and that models generate outputs that permit adequate evaluation of the relative risk between business lines and to provide suitable trend analysis. Although there is scope for practices to improve further, the signs of progress in these areas are moderately encouraging.

In other respects industry validation practices are weak, particularly when the total capital adequacy of the bank and the overall calibration of the model is an important consideration. It is recognised that this validation task is intrinsically difficult since it will typically require evaluation of high quantiles of loss distributions over long periods combined with data scarcity coupled with technical difficulties such as tail estimation. Moreover, it is recognised that validation practices will depend on what the model is being used for. Nevertheless, difficult as the validation task might be, weaknesses in validation practices targeted at evaluation of overall performance might result in banks operating with inappropriately calibrated models. This could be of concern if assessment of overall capital adequacy is an important application of the model. Improvements in these areas could include further benchmarking and industry-wide exercises, backtesting, profit and loss analysis and stress testing.

Additionally, institutions should recognise clearly that when validation is difficult and has limitations, ie when for one reason or another models cannot be appropriately validated, users of those models and senior management should be informed that full validation could not be conducted. Such communication is necessary so that model users and senior management understand that there is greater uncertainty around the output from models that have not been validated and that such model output should generally be treated with extra conservatism. In that vein, model users and senior management should understand and explore the potential costs of using models that have not been fully validated (ie, if key assumptions in the models prove to be inaccurate). 


\section{Annex 1 \\ Dependency modelling in credit risk models}

A particularly important and difficult aspect of portfolio credit risk modelling is the modelling of the dependency structure between borrowers. This encompasses linear and non-linear dependency relationships between obligors. Dependency modelling is important because it forms an important distinction between the Basel II risk weight function (with supervisory imposed correlations) and portfolio credit risk models which rely on banks' internal modelling of dependencies.

Understanding the way dependencies are modelled is important for supervisors when they assess a bank's ICAAP under Pillar 2, since internal bank modelling of portfolio credit risk may be an important element of a bank's ICAAP and can generate the biggest reduction of capital needs in comparison with the Pillar 1 minimum capital requirement for credit risk.

This annex briefly describes the main methods used for modelling credit dependencies and discusses progress since the publication of the BCBS (1999) report. It also discusses the impact that different methods have on banks' economic capital, and makes some observations linked to recent developments in dependency modelling. Finally, it raises some supervisory concerns about the current state of industry practice.

\section{A. Types of models}

The majority of banks use one of three types of credit models. These models, often referred to by their commercial names, are Moody's/KMV (MKMV), CreditMetrics, and CreditRisk+. The annex follows the same convention even though other vendors offer similar models and some banks have developed their own internal models that are consistent with the structure of one of these model types. ${ }^{24}$

Most models of credit portfolio risk estimate asset correlations among obligors in terms of common dependence on systematic risk factors. The assumption is that these underlying factors - eg country, region or industry of a borrower - fluctuate over time and typically follow a (joint) normal distribution. All borrowers are linked to these underlying systematic risk factors to varying degrees and tend to move in a correlated way. Thus, by modelling dependencies, banks account implicitly for concentration (both single name and sectoral) because large parts of their books are subject to the same underlying risk factors or to multiple risk factors.

Extensions of the three credit portfolio models are used by some banks. For example, this is the case for a few banks with specialised portfolios (eg small and medium-size European corporate loans) which have integrated a contagion approach into variants of the standard

24 The discussion of these model types is descriptive and is not intended as an endorsement of any of the vendor models. Reference to these prototype models should not be construed as an endorsement of these models, or as an indication of their standing relative to other models that might be used by banks or offered by other vendors. 
credit portfolio models (see Box 1). By integrating information on business relationships among borrowers into the credit portfolio model, this approach tries to address the clustering of defaults observed within their portfolios that are linked to bank specific portfolio concentration and exposure mix.

In addition, few banks model dependencies using copulas (see Box 2), at least for their economic credit risk modelling. This technique can be used to capture several alternative general types of dependencies, as opposed to the more restrictive Gaussian copula models. ${ }^{25}$

Some banks also use models that are based on the asymptotic single-risk-factor (ASRF) model, which is the basis for the Basel II risk weights for credit risk. ${ }^{26}$ Within this modelling approach, banks may use their own estimates of correlations or may use multiple systematic risk factors in order to address concentrations. Such a modelling approach raises several supervisory concerns about the method used to calibrate the correlations and the ways in which the bank addresses the infinite granularity and single-factor structure of the ASRF model.

Under the impetus of the Basel II Framework, banks have also increased their use of bottomup approaches in their credit risk dependency modelling. As a result, credit portfolio models are much more integrated into daily risk measurement and management than was the case in 1999.

\section{The IACPM and ISDA study}

Given the differing approaches to modelling dependencies between borrowers described above, the question arises as to what extent the economic capital estimates produced by the models differ from each other. To shed some light on this empirical question, the International Association of Credit Portfolio Managers (IACPM) and International Swaps and Derivatives Association (ISDA) conducted a study in 2006 to explore the economic credit capital models in use by their member institutions.

The IACPM and ISDA (2006) study evaluated the degree of convergence of economic capital estimates across commercially available credit portfolio models and across internally developed credit risk models implemented by banks. Given that most banks use one of the three main commercially available credit risk models mentioned above or internally developed implementations of the same types of models, the study was effectively a comparison of the economic capital estimates generated by these commercially available models, run either in default mode or in mark-to-market mode. ${ }^{27}$ The study applied the different credit models to a representative portfolio of transactions that was assembled with pre-specified data assumptions regarding risk characteristics. By eliminating different data characteristics and portfolio composition as sources of potential differences in economic capital estimates, remaining differences are largely due to differences in the modelling

25 See for example Hull (2007) for a discussion of copulas.

26 The ASRF model is also referred to as a single-factor Gaussian copula model. For this model, the capital charge for an exposure depends on the risk characteristics of this exposure only (i.e. PD, LGD, EAD, maturity) and does not depend on the composition of the portfolio to which the exposure is added .

27 Credit Risk+ is exclusively a 'default mode' model. Default mode refers to the situation where credit losses arise only if a borrower defaults within the planned time horizon. Mark-to-market credit losses can arise in response to deterioration in an asset's credit quality before the end of the planning horizon. 
approaches. Outcomes of the study may also be dependent on the composition and characteristics of the test portfolios used in the study.

The study showed significant differences in economic capital estimates between the different models, in default-only mode as well as in mark-to-market mode. The differences in economic capital estimates between the models can be explained in terms of the following factors: correlation structure; treatment of interest payments due between time zero (point of valuation) and the time horizon (point of default) and whether this was accounted for in the definition of loss; and other modelling differences.

Of special interest in the context of this annex is the question: How much of the difference in economic capital is due to correlation structure/dependency modelling assumptions? In default-only mode, the differences could be explained to a large extent by the different treatment of interest payments (ie by the difference in definition of loss), with the correlation structure playing only a minor role. However, in mark-to-market mode, where changes in revaluations at the horizon for non-defaulted assets may also be correlated, and where the impact of differences in the modelling of correlations is larger, roughly a quarter of the observed difference in economic capital estimates is attributable to correlation assumptions.

Another issue involves the sensitivity of economic capital estimates to changes in portfolio concentrations and model parameters. Sensitivity analysis performed in the IACPM and ISDA study showed that a change in the sector or country composition of the representative portfolio had a large impact on economic capital estimates. ${ }^{28}$ Furthermore, the impact differed between the different types of credit risk models. This evidence provides empirical support for the notion that the output of credit risk models significantly depends on the underlying correlation structure. Differences in correlations could be structural in nature since different models may use different data to calibrate correlations (eg historical equity returns versus default rate data), or could be due to time-varying correlations. ${ }^{29}$

\section{B. Supervisory concerns relating to currently used credit portfolio models}

\section{Shortcomings of dependency modelling}

Regarding dependency assumptions used in credit portfolio models, supervisors can question the accuracy and robustness of correlation estimates used by banks since these estimates depend heavily on (explicit or implicit) model assumptions and can significantly influence economic capital calculations. These assumptions are even more problematic when the dependency modelling and calibration methods used are embedded in proprietary third-party vendor credit risk models, which essentially can be viewed as "black boxes."

Beyond the issues raised by the basic approaches used in structural and reduced-form credit portfolio models, the validity of several other assumptions has been examined in the academic literature. For example, the validity of the following assumptions has been drawn into question: the asymptotic single-factor Gaussian copula approach; the normal distribution for the variables driving default; the stability of correlations through time; and the joint

28 For example, it could double the amount of economic capital for credit risk.

29 The IACPM and ISDA study concludes that when loss assumptions are aligned across both vendor and internal credit portfolio models, estimates of economic capital for credit risk can be shown to converge for default-mode models. Differences in the capital estimates for mark-to-market models can be reduced, but not eliminated. 
assumptions of correctly specified default probabilities and doubly-stochastic processes, which imply that default correlation is adequately captured by common risk factors.

Several academic papers question the ability of some models using such assumptions to explain the time-clustering of defaults that is observed in some markets. This in turn, when combined with inadequately integrating the correlation between PD and LGD in the models and inadequately modelling LGD variability, can lead to an underestimation of economic capital needed. In addition, it will make it difficult to identify the different sources of correlations and the clustering of defaults and losses .

For example, Das et al (2007) found that US corporate default rates between 1979 and 2004 vary beyond what can be explained by a model that only includes observable covariates. Moreover, Duffie et al (2006) found evidence of the presence among U.S. corporate default rates of one or more unobservable common sources of default risk that increase default correlation and extreme portfolio loss beyond that implied by observable common and correlated macroeconomic and firm-specific sources of default risk. ${ }^{30}$ However, there are practical limitations of the "frailty approach" (ie modelling default clustering with latent risk factors) including the computational cost, and the failure to identify the frailty factor, hampering the ability of banks to make practical decisions in managing the risk from the frailty factor.

With respect to the stable correlation hypothesis, Bangia et al (2000) found that rating transitions are sensitive to the business cycle and are explained by different models during expansionary and recessionary periods. Therefore, the sample period and approach used to calibrate the dependency structure could be important in assessing whether correlation estimates are overestimated or underestimated, and therefore whether they should be reviewed.

Other assumptions can also impact correlation calibration. For example, when a model assumes that unobservable asset returns can be approximated by changes in equity prices, it does not account for the fact that the relationship between asset returns and equity prices is unobservable and could also be non-linear. Similarly, when equity prices are used to estimate credit default probability, the issue arises that although such prices can cover a wide range of industries and geographical locations, they also reflect information that is unrelated to credit risk. Consequently, the use of equity prices can introduce some noise in the correlation estimates.

On the other hand, when banks use a regulatory-type approach, with single or multiple risk factors, the assumptions of such an approach poses two important issues for both banks and supervisors:

- $\quad$ Since the correlation estimates are explicit parameters in the Basel ASRF model, they would need to be estimated. There may be limited historical data on which to base the correlation estimates, and the assumptions used to generate the correlations may not align with the underlying assumptions of the Basel II credit risk model.

- If a bank uses the Basel II risk weight model (either with supervisory or with its own correlations), it must account for concentration risk (single name and industry/

30 As pointed out by Das et al (2007) and others, known factors account for a very large fraction of the default correlation observed in the data. As a result, a practical approach to overcoming the shortcoming of the frailty factor is to use conservative estimates of asset correlations and to conduct stress testing. 
regional concentrations) by other measures and/or management methods (eg limit setting), and supervisors will have to evaluate these approaches.

The concern about assumptions is important since they can have a significant impact on measures of portfolio credit risk and the measurement of economic capital. For example, Tarashev and Zhu (2007) demonstrate, by comparing the loss distributions produced by the KMV and the ASRF models, that the single-risk-factor and infinite granularity assumptions of the ASRF model have small impacts on measurement of capital needs, especially for large, well-diversified portfolios. By contrast, the use of misspecified or incorrectly calibrated correlations and the use of a normal distribution (which fails to replicate the tails of the distribution of asset returns) ${ }^{31}$ can lead to significant inaccuracies in measures of portfolio credit risk and economic capital.

\section{Use of credit dependency modelling}

One of the main supervisory concerns is that some banks use credit portfolio models without always having a full understanding of all the underlying assumptions and modelling techniques embedded in them. Whether such models are suitable for different portfolios (retail, structured products, etc.) as well as for the specific concentration and exposure mix characteristics of their own portfolios should be assessed.

For example, it seems that the use of asset return correlations derived from equity prices has become a market standard for portfolios of large corporates, despite the limitations associated with such an approach.

It is important to consider whether the uncritical use of asset correlations for other portfolios such as SME and retail borrowers is adequate. The estimated correlations could be meaningfully used as long as they are applied to large, publicly traded borrowers. The appropriateness of using such data to estimate correlations for other exposures such as nontraded, small and medium-sized enterprises and retail borrowers is less clear. Specifically, corporate, SME and retail portfolios are data-rich, which means that the derivation of different default correlations from internal bank data could be envisaged in some cases. For non traded SME portfolios, there are third-party vendors that might also provide relevant data for some local markets.

However, banks do not generally calibrate their retail and SME correlations separately. Instead they use shortcuts, such as assigning retail borrowers to the no industry category in a credit portfolio model. It remains to be seen whether these shortcuts provide a meaningful measure of risk for SME and retail portfolios.

The use of more complex models (eg contagion models and Gaussian and non-Gaussian copulas), which need technical, judgemental and modelling expertise, could also be viewed as too burdensome, uncertain, unstable or inappropriate to implement. Assuming that banks gather enough data to estimate more reliable correlations using internal data in the future, it would be useful for the industry to make progress in estimating correlations for other exposures, such as SME, retail, and structured products, and to analyse which data, models, and techniques are the most relevant for these portfolios.

31 With respect to the loss distributions, they are more likely to follow double-t distributions with medium to high degrees of freedom instead of normal distributions. Such misspecification can imply an underestimation of economic capital that ranges from $22 \%$ to $86 \%$. 


\section{Box 1: Contagion approach}

Motivated by the financial crises in South East Asia and the US in the 1990s, and the Enron default crisis in late 2001, where the downfall of a small number of firms had an economywide impact, academic researchers have attempted to incorporate counterparty relationships, or microstructure correlation, into portfolio credit models (Davis and Lo (2001), and Jarrow and $\mathrm{Yu}(2001)$ ). The common feature of contagion models is that they distinguish between macrostructure and microstructure dependencies. In contrast to macrostructure dependencies, microstructure dependencies attempt to capture business relationships and legal dependencies within and across sectors. This approach is also relevant for pricing CDSs, CDOs, and basket derivatives, since the prices for these products are influenced by dependencies between the firms in a basket, a business (eg suppliers and competitors), etc.

The microstructure contagion effect can be integrated using different approaches, (eg reduced-form models). The idea behind contagion models is that contagion risk produces upward jumps in the default intensity of non-defaulted firms, implying a higher conditional default probability for these firms given additional information on other firms' defaults. The driving principle behind such modelling is that considering only macroeconomic dependencies for a portfolio subject to microstructure dependencies could potentially underestimate credit risk. By integrating microstructure dependencies into the model, the standard deviation of rating changes over time is increased, even for well-diversified credit portfolios with moderate microstructure dependencies.

Generally, the contagion approach is supposed to be conservative since it lengthens the tail of the loss distribution and therefore increases the capital needed to cover credit risk. However, it is difficult to gauge whether the increase in capital is sufficient to capture the risk dependencies. Additionally, practical and theoretical issues need to be addressed, such as the reliability of the required expert judgement and ability to identify the frailty/contagion factors. 


\section{Box 2: Copulas}

Some banks model dependencies using copulas. Within the context of credit risk modelling, copulas are used to model dependencies between the defaults of credit obligations in a portfolio. Given that one obligor has defaulted, other obligors in the portfolio might be more likely to default because they are connected to the defaulted obligor directly (eg if the defaulted obligor is the creditor of another) or indirectly (eg if another obligor is in the same industry).

For a collection of random variables with given marginal distributions (the univariate probability distribution of each random variable) a copula specifies how these random variables combine into a multivariate distribution, and thus specifies the dependencies between the random variables. Some copulas like the Gaussian copula are characterised by a correlation matrix, while other copulas describe dependencies that are non-linear or too complicated to be accurately described by correlation parameters. A copula is a mapping that transforms the marginal distributions for a collection of random variables into a joint distribution for all the random variables.

When copulas are used in credit risk modelling, the underlying random variables of interest may be the time to default of each obligation in a portfolio, or in Merton type models, the asset values of the obligors. In the latter case, the obligor defaults when its asset value falls below a certain threshold. These underlying variables are continuous random variables, and they express the likelihood of default in a different way from the more familiar (discrete) indicator random variables, which are 1 if default occurs during a specified period and 0 otherwise. If $q_{i}$ is the underlying random variable denoting for example the time to default of obligor $\mathrm{i}$, and $\mathrm{I}_{\mathrm{i}, \mathrm{T}}$ is the indicator random variable denoting default before time $\mathrm{T}$, the relation between $\mathrm{q}_{\mathrm{i}}$ and $\mathrm{l}_{\mathrm{i}, \mathrm{T}}$ is:

$$
I_{i, T}=\left\{\begin{array}{l}
1, \text { if } q_{i} \leq T \\
0, \text { if } q_{i}>T
\end{array}\right.
$$

If the distributions of these time-to-default variables are combined using a copula, a joint distribution function for the time-to-default variables is obtained. Taking random samples from this joint distribution, and given a specified time horizon, each sample from the distribution will translate into a set of defaulting and non-defaulting obligations within the portfolio over that time period.

The first copula to be widely used in the context of credit modelling was the Gaussian copula. One important shortcoming of the Gaussian copula is that it displays zero tail dependence. Besides the Gaussian copula, copulas based on other multivariate distributions (particularly the Student-t distribution) are often used with the goal of capturing dependencies between defaults that have a stronger impact on the tail of the loss distribution. For example, the tcopula has a parameter for "tail association" or dependence. The distributions produced by copulas are usually not tractable analytically, and as a result, copulas are most frequently used in running portfolio default simulations. 


\section{Annex 2}

\section{Counterparty credit risk}

Counterparty credit risk (CCR) at large, complex banks centres on the measurement and management of financial exposure and the resulting credit risk associated with core credit extension activities of these financial institutions to a wide range of counterparty types. Counterparty credit risk takes a variety of forms, including credit risk emanating from activities in OTC and exchange-traded derivatives, from securities financing activities, and from foreign exchange settlements. The counterparties to these financial institutions take a wide variety of forms, ranging from sovereigns and local government entities, to regulated financial concerns and potentially unregulated financial parties such as hedge funds, to corporate entities (both investment-grade and below-investment-grade).

This annex is organised as follows. Section A highlights the challenges that the industry faces in quantifying counterparty credit risk for economic capital purposes, while Section B addresses the range of practices that financial institutions undertake in quantifying this risk. The primary focus is on modelling challenges in the quantification of counterparty credit risk, and thus there is no explicit consideration of the comprehensive set of risk management practices that are meant to mitigate risks or to provide compensating controls for model deficiencies, unless those practices (such as initial margin and ongoing collateral practices related to counterparty credit risk) directly influence the quantification of risk.

\section{A. Counterparty credit risk challenges}

Measurement of counterparty credit risk represents a complex exercise, as it involves gathering data from multiple systems; measuring exposures from potentially millions of transactions (including an increasingly significant percentage that exhibit optionality) spanning variable time horizons ranging from overnight to thirty or more years; tracking collateral and netting arrangements; and categorising exposures across thousands of counterparties. The complexities of the processes highlighted below indicate a need for institutions to have specialised processes and personnel to tackle these issues and challenges.

\section{Measuring exposure and measuring risk}

A bank's counterparty credit measurement can be conceptually broken down into two distinct steps. First is the measurement of counterparty credit exposure - that is, how much money the counterparty will owe the bank in the event of default This exposure number is further broken down into current exposure, which measures the exposure if the counterparty were to default today, and potential exposure, which measures the potential increase in exposure that could occur between today and some time horizon in the future. One feature of derivatives and securities financing relationships is that, while the amount of current exposure to a counterparty is known, the amount of potential exposure to a counterparty is an unknown quantity (in fact, given the nature of derivatives contracts and securities financing arrangements, there may be no exposure to the financial institution at the time of a counterparty default). Therefore, counterparty credit exposure is generally measured as 
some statistic (such as a mean or a percentile) of the distribution of possible future exposures to the counterparty.

The second part of the counterparty credit measurement is converting the exposure to a risk amount for economic capital purposes or risk management purposes more generally (for example, to inform a counterparty credit risk limit system). The risk measurement will be a function of the probability of default (PD) for the counterparty, the loss given default (LGD) for the exposure, and the exposure measurement, which is effectively the exposure at default (EAD) value. The EAD value is driven by market-risk-related factors (the volatility and correlation among market risk factors and how they affect the derivative contract or valuation of the securities being financed), while the PD and LGD are effectively determined by firm's assessment of the credit quality of the counterparty.

Counterparty credit risk measurement, therefore, necessarily combines the tools from standard market risk measurement with the tools from standard credit risk determination. Market risk measurement practices are used, for example, in mapping derivatives exposures to a set of market risk factors, simulating those factors out to a forward-looking time horizon, and determining the distribution of the level of exposures over various risk factor realisations in the simulation. Separately, standard credit risk processes provide assessments of the credit quality of the counterparty, frequently resulting in a credit rating of the counterparty, both from the PD and LGD perspectives. Counterparty credit risk measurement offers unique challenges related to both the market-risk-related and the credit-risk-related processes, which are described next.

\section{Market-risk-related challenges to counterparty EAD estimation}

Counterparty credit exposure measurement requires simulation of market risk factors and the revaluation of counterparty positions under the simulated risk factor shocks, much like a value-at-risk (VaR) model requires. Two unique challenges present themselves when attempting to leverage a VaR model technology for counterparty credit exposure measurement.

First, market risk VaR models combine all positions in a portfolio into a single simulation, so that gains from one position are allowed to fully offset the losses in another position in the same simulation run. Counterparty credit risk exposure measurement, however, cannot allow netting across counterparties (eg a decline in exposure to one counterparty cannot be netted against an increased exposure to another counterparty). Therefore, the analysis of counterparty exposure must be done at the 'netting set' level (that is, on each set of transactions that form the basis of a legally enforceable netting agreement). Most banks have many thousands of counterparties, and each of these counterparties may have many different netting agreements (segregated, for example, by product type or legal jurisdiction). This situation, therefore, requires the counterparty exposure measurement to perform a calculation at the netting-set level, thereby increasing the computational intensity of the calculation.

Second, market risk VaR calculations are traditionally performed for a single short-term holding period - for example, for a single day or a ten-day holding period. Counterparty credit exposure measurement, however, must be performed for multiple holding periods into the future, as certain derivatives contracts, for example, can extend years, or even decades, into the future. As a result, market risk factors have to be simulated over much longer time periods than in the standard VaR calculation, and revaluation of the potential exposure in the future must be done for the entire portfolio at certain points in the future. 
The combination of the large number of counterparties and the large number of holding periods in the future implies that the computation challenges in effectively measuring VaR are dramatically increased when financial institutions attempt to measure counterparty exposures for derivatives transactions. As a result, a bank may decide to reduce the number of market risk factors considered in the simulation for counterparty credit risk relative to the number considered in the market risk VaR calculation. The resulting simplification can result in a reduction in precision of the final result, but the materiality of the reduced precision is highly dependent on the circumstances of the positions relative to the model. For example, ignoring the volatility smile in a business with few trades might not be material, but using a single-factor term structure of interest rate model may result in significant reduction in accuracy of the model for these exposures.

\section{Credit-risk-related challenges to PD and LGD estimation}

Frequently, counterparties to financial firms for derivatives or securities financing transactions have other credit-risk-related relationships, so that the financial firm would already have a credit rating, and an associated PD and ability to calculate an LGD for the exposure. However, some important derivatives and securities financing activities are done with counterparties (such as hedge funds) with which the financial institution may have no other exposures. In those cases, the financial firm must determine a PD and LGD associated with the counterparty and the facility. In the case of hedge funds, the counterparty may have little transparency in terms of underlying fund volatility, leverage, or types of investment strategies employed, which creates a significant challenge. In the cases of counterparties to which the institution has other credit exposures (eg a corporate client), the institution will typically be using the same PD used for the other exposures, but will need to arrive at a facility-specific LGD.

\section{Interaction between market risk and credit risk - Wrong-way risk}

While counterparty credit risk can conceptually be broken down into a market-risk-driven EAD calculation and a credit-risk-driven PD-LGD determination, these two processes are frequently not independent. This interaction, where PD and LGD may tend to rise at the same time as the exposure to the counterparty is rising, is known as "wrong-way risk." For counterparty credit exposure systems that separate EAD estimation from PD-LGD estimation, the incorporation of wrong-way risk in the economic capital calculation is not directly feasible, but may be incorporated via an add-on in the economic capital process. Challenges arise when trying to capture wrong-way risk. Wrong-way risk is sometimes difficult to identify, as it requires understanding the market risk factors that the counterparty is exposed to, and relating those factor sensitivities to the factor sensitivities of the institution's own exposures to the counterparty. Understanding the counterparties' risk factor sensitivities can be challenging, especially for counterparties (such as some hedge funds) that tend to be opaque. Even when wrong-way risk can be identified directionally, it is often difficult to quantify its magnitude in an economic capital model (in particular, over a one-year horizon at a high confidence level).

\section{Operational-risk-related challenges in managing counterparty credit risk}

Managing counterparty credit risk is a very resource-intensive activity, and requires specialised systems and personnel to effectively implement. Daily limit monitoring, markingto-market, collateral management processes, and intraday liquidity and credit extensions are all complicated and interlinked processes that give rise to the possibility of operational risk difficulties. Such operational risk exposure is generally not captured for economic capital 
purposes within counterparty credit risk, but may be captured within an operational risk quantification process. Operational risks related to counterparty risk that are particularly difficult to quantify involve risks of new or rapidly growing businesses, risks in new products or processes, risks in intraday extensions of credit which are not properly captured in systems designed for end-of-day exposure capture, and risks in areas where there have been few historical instances of losses but where potential "tail events" may have severe consequences.

\section{Differences in risk profiles between margined and non-margined counterparties}

One important input in the measurement of counterparty credit risk among firms' counterparties is whether the counterparty is a margined counterparty or not. A margined counterparty has agreed to post collateral, either in the form of cash or securities, when their exposure to the financial firm is positive. While there are wide variations in the practices surrounding margining of counterparties (minimum thresholds before a margin call is made, the frequency of margin calls, the treatment of valuation of illiquid products, etc.), an important distinction in the modelling approaches must be made between counterparties who have agreed to margining (also known as 'having a CSA' - a credit support annex to the master netting agreement that lays out the terms of the margining agreement) and those who have not. Frequently, the modelling difference between these classes of counterparties surrounds the treatment of the look-ahead forecasting period: For margined counterparties, the forecasting period is short, associated with a reasonable 'cure period' between when a counterparty misses a margin call and when the underlying positions can be closed out; for non-margined counterparties, the forecasting period is generally much longer, as long as the life of the contract. The variation in modelling horizons makes the aggregation of risk across these two classes of counterparties a challenge, as most risk modelling approaches take a single modelling horizon (eg one day for VaR models, one year for economic capital models) for all positions. Aggregation is further complicated if, for a given counterparty, some positions are margined but others are not.

Note that there still is a gap risk, even for margined counterparties, which needs to be modelled and accounted for. In stress situations that adversely affect the assets being financed, there could be a risk of market gapping and rapid loss of value. Banks may need to take possession of collateral at a time when its value is deteriorating and the market for it may be illiquid. This risk may be amplified by the presence of exposure concentrations within the firm, or by "crowded trades," where several firms may be taking possession of similar collateral and seeking to liquidate it at the same time.

\section{7. $\quad$ Aggregation challenges}

While calculation of counterparty credit risk for an individual counterparty has its challenges, these challenges are magnified when attempting to get a firm-wide view of risk for economic capital purposes. Independently of the challenges in arriving at a counterparty credit risk economic capital measure outlined above, this risk measure must be aggregated in a sensible, rigorous, and risk-sensitive way with other exposures at the financial firm in order for the overall economic capital measure to be a reliable indicator of the aggregate inherent risk-taking by the firm. If a single counterparty has both derivatives and securities financing transactions, the firm may face challenges in aggregation across the counterparty's exposures, as the various models and systems architectures may not be conducive to aggregation. Furthermore, a firm's counterparty credit risk must be aggregated with other credit risk-taking activities of the firm, both in terms of loans in the banking book and credit risk in the trading book. Finally, these more comprehensive credit risk measures must be 
aggregated with overall market and operational risk in order to arrive at the final economic capital measure.

A related challenge involves the ability of the counterparty credit risk system to allow risk management to have a detailed understanding of the various breakdowns of risk that are common in the market risk world. Breakdowns by product, by risk factor, by geography, by business line, or by legal entity are difficult for many firms to produce, for a variety of reasons. The computation intensity of the calculations makes the provision of such "drill down capabilities" expensive in terms of time to produce on a daily basis. Fragmented computer systems and IT infrastructures, frequently driven by a variety of legacy infrastructures from merger and acquisition activity, are frequently cited culprits to the limitations associated with counterparty credit risk systems' lack of flexibility. The IT requirements associated with Basel II's internal models approach to the use of counterparty credit risk for regulatory capital purposes were often mentioned as a possible mechanism to address some of the existing systems' rigidities, but it remains uncertain how much of the planned IT investments will address the existing systems' limitations.

\section{B. Range of practices}

Given the variation in size and complexity of counterparty credit exposures across large financial firms, these institutions display a range of practices in measuring CCR for economic capital purposes. Firms employ one of two general modelling approaches to quantify the counterparty credit risk exposures. While these models may be supplemented with complementary measurement processes, firms typically have adopted one of two measurement "engines":

The first is a stand-alone simulation engine, typically implementing a Monte Carlo approach ("Monte Carlo Model"). This simulation normally spans a long forecasting horizon - often encompassing the contractual life of the transaction -- and then selects an average exposure measurement or a percentile of the resulting exposure distribution to quantify the exposure for a transaction or a portfolio of transactions at different points in time over the forecasting horizon. The banks employing this approach for collateralised counterparties will typically use the same approach to measure uncollateralised counterparty exposures.

The second approach is a "value-at-risk" ("VaR")-type CCR exposure engine ("VaR Model"), typically achieved by leveraging the firm's existing market risk VaR processes. This approach estimates the distribution of CCR exposures over a relatively short-term liquidation (or "closeout") horizon. The banks employing this approach for collateralised counterparties still typically use a Monte Carlo approach to measure uncollateralised exposures with longerterm horizons.

The decision of whether to use Monte Carlo Model or VAR-type model to quantify CCR exposures for collateralised counterparties involves a variety of trade-offs.

The VaR-type model leverages well-developed and already validated data and analytical systems, thereby permitting usage of a large set of risk factors deployed for market risk measurement. Due to the computational intensity, however, the VaR-type model is practical only for quantifying the exposure profile over a single short-term forecasting horizon, which can be utilised for collateralised counterparty credit risk assessments. Consequently, the VaR-type model exhibits the limitation that it cannot produce a profile of exposures over time, which is necessary for counterparties that are not subject to daily margining agreements. 
The Monte Carlo model, on the other hand, allows for the quantification of longer-term exposures but at the potential expense of a less accurate measurement of CCR exposure given the necessary use of simplified risk factor representation.

\section{Use of add-ons}

Counterparty credit risk engines may not effectively capture the risks of all financial products. For products not effectively captured by counterparty credit exposure measurements, many firms revert to an "add-on" factor, which provides a simplified but conservative measurement of the exposure for that product. While generally calibrated to be conservative, the add-on factors are frequently not risk sensitive (eg the factors may not change as market volatility rises and falls) and frequently do not allow for netting, hedging or diversification effects across risk factors.

\section{Counterparty credit risk processes for high risk counterparties}

Firms continue to be challenged by the opacity of risks for certain counterparties, such as hedge funds, and have developed enhanced processes to identify, measure, monitor, limit, control and report the risks from these counterparty relationships.

\section{Ancillary processes to view counterparty credit risk}

Due to the challenges of developing a highly nuanced view of counterparty credit risk for economic capital purposes, banks have developed ancillary processes to help manage and measure these risks. Concentration risk identification and stress testing are two of the key risk management processes that attempt to quantify the risks in counterparty credit relationships that may be poorly measured by the core counterparty credit risk engines. Concentration risk identification involves a set of ancillary analytics, mostly outside of the main counterparty credit risk engine, which attempts to identify large exposures by individual counterparty, by the set of counterparties of lower credit ratings, by underlying risk factor, or by other dimensions that the firms have identified as important measures of concentration that are deemed worthy of monitoring. However, one should keep in mind that concentration of positions with larger counterparties - ones that may actually enjoy enhanced diversification benefits during moments of stress - may be less harmful than the aggregate exposure of trades with a collection of smaller counterparties.

Stress testing, also performed outside of the main counterparty credit risk engines, involves a variety of diagnostic tools designed to identify risk vulnerabilities that the main risk engine may not capture or identify. Stress tests, however, are frequently not fully comprehensive of all counterparty credit risk exposures. Stress tests may be performed on a subset of the entire universe of counterparties (for example, on only counterparties that do not have daily margining agreements, or on only 'highly leveraged' counterparties). Sometimes, not all counterparty positions are included in the stress tests (for example, positions that are treated with "add-ons" may be excluded from the stress tests, as the simple add-on may deemed to be a sufficiently conservative treatment of the risks for stress testing purposes). Finally, stress tests are frequently treated as a diagnostic tool of risk management, and may have no associated limits or escalation procedures associated with them.

Additionally, while wrong-way risk may be missed in the main counterparty credit risk quantification process, many firms have separate processes to measure and to limit the level of wrong-way risk in their counterparty credit risk relationships, where it can be measured. 


\section{Haircut determination for securities financing activities}

The processes for determining haircuts for securities financing activities generally do not consider stressful market conditions, but are based on the range of historical experience, including normal market environments. When economic capital is calculated for these positions, however, the market risk factors are shocked to a stressed level, and the risks beyond the haircut are included in the determination of economic capital of the securities financing activity.

\section{Counterparty credit risk model validation}

Counterparty credit risk models for economic capital purposes generally do not have specialised validation processes associated with them, but rather use the results of validation work done by others, such as by risk management, to support the use of the counterparty credit risk model. When there is a difference between the counterparty credit risk model for economic capital purposes and the counterparty credit risk model for risk management purposes (for example, the holding period may vary), there appears to be little additional testing or validation to support the difference, as the differences are generally viewed as mechanic differences in implementation and not as separate models requiring separate validation. For example, backtesting, an established practice for market risk exposures, is still in the early stages of development for counterparty credit risk models. 


\section{Annex 3}

\section{Interest rate risk in the banking book}

Interest rate risk refers to the exposure of a bank's financial condition to adverse movements in interest rates. It should be interpreted for the purposes of this annex as the current or prospective risk to both the earnings and capital of an institution arising from adverse movements in interest rates, which affect the institution's banking book. Changes in interest rates affect an institution's earnings by altering interest-sensitive income and expenses, and the underlying value of an institution's assets, liabilities, and off-balance sheet instruments because the present value of future cash flows changes when interest rates change. ${ }^{32} \mathrm{An}$ indirect effect can also occur, which is linked to the impact that rate changes can have on business volumes. Although interest rate risk in the banking book is a normal part of financial intermediation, excessive interest rate risk poses a significant threat to an institution's earnings and capital adequacy.

The main challenges in the calculation of economic capital for interest rate risk in the banking book come from the long holding period assumed for a bank's structural balance sheet and the need to model indeterminate cash flows on both the asset and liability side due to the embedded optionality of many banking book items.

Many banks use some type of internal transfer funds pricing to move structural interest rate into a centralised place within the organisation, typically the bank's treasury unit, in order to achieve matched funds transfer pricing between all other business units of the bank. This unit is responsible for interest rate modelling and maintaining gap positions within agreed upon risk limits.

\section{A. Sources of interest rate risk}

The main sources of interest rate risk in the banking book are repricing risk (arising from differences in the maturity and repricing terms of customer loans and liabilities), yield curve risk (stemming from asymmetric movements in rates along the yield curve), and basis risk (arising from imperfect correlation in the adjustment of the rates earned and paid on different financial instruments with otherwise similar repricing characteristics).

Interest rate risk in the banking book also arises from the option features of many financial instruments. ${ }^{33}$ Retail products in the banking book that have embedded options include bonds and notes with call or put provisions, loans such as mortgages which give borrowers the option to prepay balances, adjustable-rate loans with explicit interest rate caps and floors

32 Interest rate risk arises from the natural mismatch between repricing characteristics desired by investors and depositors and those desired by borrowers. As such, interest rate risk derives from the mismatched maturities or durations of assets which are typically longer than the liabilities. A sudden change in the shape of the term structure will affect the values of assets differently from those of liabilities.

33 According to Principle 16 of the Basel Committee's Principles for the Management and Supervision of Interest Rate Risk (BCBS, 2004), "An additional and increasingly important source of interest rate risk arises from the options embedded in many bank assets, liabilities, and off-balance sheet portfolios." 
that limit the amount by which the rate may adjust, and various types of non-maturity deposits which give depositors the option to withdraw funds at any time often without penalty. If not adequately measured and managed, the asymmetrical payoff characteristics of instruments with embedded option features can pose significant interest rate risks.

\section{B. Interest rate measurement techniques and indicators}

There are two basic techniques for assessing interest rate risk in the banking book: repricing schedules (gap and duration analyses) and simulation approaches. Although commonly used, the simple structure and restrictive assumptions make repricing schedules less suitable for the calculation of economic capital. ${ }^{34}$ Most banks use simulation approaches for determining their economic capital, based on estimated losses occurring in case of a set of worst case scenarios. The magnitude of such losses and their probability of occurrence determine the amount of economic capital.

The banking book is traditionally based on accrual accounting and measures such as earnings volatility or Earnings at Risk (EaR) are used. EaR measures the loss of net interest income resulting from interest rate movements, either gradual movements or one-off large interest rate shock, over a given time horizon (typically one to two years). A disadvantage of the EaR method is that it only measures the short-term earnings effect (accrued interest) resulting from interest rate fluctuations and not the economic value effects (capital gains/capital losses).

Some banks have moved towards an economic value orientation and measures based on Economic Value of Equity (EVE), VaR and Extreme Value Theory (EVT) are becoming popular. EVE, which is defined as the present value of assets minus liabilities, measures the change in the market value of equity resulting from interest rate shock scenarios, compared with the market value of equity under a base scenario. It is a comprehensive risk measure, consistent with the Basel standard interest rate shock used to identify outliers. ${ }^{35}$ The accuracy of the valuation of balance sheet positions is strongly dependent upon the calculated cash flows and discount rates used. ${ }^{36}$ For practical purposes, most EVE models use static or liquidation concepts, in the sense that they show a snapshot in time of the risk based upon the current portfolio or balance sheet composition. In principle, EVE may be adapted to allow for the rolling over of current positions. In its dynamic version EVE may provide forward risk measures that also take into account future growth in existing or new business activities.

When the EVE model is complemented with an estimate of the probabilities of the interestrate scenarios used, the EVE model becomes a Value at Risk (VaR) model, which builds a statistical distribution of profit and losses that may occur over a specified time horizon at a

34 Particularly for larger banks, gap analysis is nothing more than the first step (in this case, the distribution of the relevant assets and liabilities according to maturity) in analyzing the interest rate risk in the banking book.

35 Under current guidelines, interest rate risk is identified as the banking book economic value sensitivity with respect to a standard interest rate shock of plus/minus 200 basis points; outlier banks are then identified as those having greater than $20 \%$ sensitivity with respect to regulatory capital.

36 When the cash flows are calculated, account needs to be taken of the fact that the size and the timing of the cash flows may differ under the various scenarios as a result of customer behavior regarding changes in deposit balances and also prepayment speeds. 
given confidence level owing to movements in interest rates. The method not only measures the magnitude of the loss, but also the probability of the loss.

In practice the calculation of economic capital follows three steps: in the first step, the change in economic value of both assets and liabilities is modelled as a result of changes in interest rates and an EVE is derived. The second step involves modelling the term structure of interest rates or the yield curve. ${ }^{37}$ Some banks model volatility changes over time, while other banks assume volatility is constant. In the third step the economic value of assets and liabilities and the term structure of interest rates are combined to produce the final value distribution which can be used to compute $\mathrm{VaR}$ or economic capital. It is worth mentioning that many of the assets and liabilities in the banking book are not regularly traded and are therefore difficult to value at market prices. Most assets and liabilities are valued on a markto-model basis, using path-dependent projections of runoff and future cash flows. ${ }^{38}$

In contrast to EVE, EVT is well suited to the estimation of extreme probabilities and quantiles of a distribution. This approach is based on the extreme value theorem, which indicates what the limiting distribution of extreme values should look like and importantly demonstrates that it is not the normal distribution. Drawbacks are the scarcity of extreme value observations, and the model risk associated with EVT estimates, which are usually very sensitive to the precise assumptions made by users.

The choice of techniques used in assessing interest rate risk depends on the bank's orientation towards either economic value or earnings, and also on the type of business model pursued by the bank. Some businesses, such as commercial lending or residential mortgage lending, are managed on a present value approach, while others, such as credit cards, are managed on an earnings approach. This poses issues when the bank wants to convert risk measures to a common metric, for aggregation purposes.

\section{Modelling issues}

The main modelling issues involve the type of simulation, the assumptions surrounding the timing of interest rate shocks, the holding period and time horizon. As for simulation, computational intensity derives from the large number of points along the term structure of interest rates, the large number of currencies to track, with different implied volatilities for each currency/term structure combination, the availability of many related, but not identical interest rate curves. Many banks adopt some dimension-reduction techniques, such as principal component analysis, to address the magnitude of the computational burden. Simulation can be static or dynamic. Static simulation models are mostly based on the current on- and off- balance sheet exposures, although they generally do take into account interest rate sensitivities of prepayments and rollovers. Some models include also expected balance sheet growth, but generally not the interest-tare-induced changes in the rate of growth, which are difficult to project. Dynamic simulation models allow for changes in business activities, incorporate optionality, prepayments, saving behaviour, etc. under different scenarios, explicitly modelling management and customer action. Although this

37 Single-factor models, such as Cox et al (1985), Black and Karasinsky (1991), or Black et al (1990) may be used, or more advanced term structure models, such as Heath et al (1992), Dai and Singleton (2000), and the lognormal forward-LIBOR model of Brace et al (1997)) may be used.

38 Although this can be true also for instruments held in the trading book, the typical short term horizon of the instruments held in the trading book provides a more frequent test of model prices. 
approach offers a more realistic setting, it comes at a cost. Dynamic models require the use of more assumptions, lead to a loss of tractability and an increase in computing time. Moreover, the longer the horizon of the analysis, the less accurate assumptions regarding future business may be. In order for economic capital numbers to be realistic, the assumptions need to be tested against internal processes and management action.

As for the type of interest rate shock, it is important to consider whether a scenario is assumed to occur gradually, giving banks time to actively manage their interest rate position, or whether an interest rate shock is assumed to occur suddenly. The pace of the interest rate movements affects interest income during the horizon of the analysis and may also affect customer behaviour, resulting in an impact on the result of the (dynamic) simulation.

When using simulation-based approaches, a time horizon should be considered that is consistent with the policy intention of holding asset and liability positions for a long period of time. For capital calculations in the banking book, typically an economic capital measure (VaR) over a short time horizon (one to ten days) is scaled up to the one-year horizon used in the economic capital framework. When scaling up VaR numbers, often the assumption is made that $\mathrm{VaR}$ realisations are independently and identically distributed over time. Factors to be taken into account in the calculation are that interest rates may be serially correlated ${ }^{39}$ and that management intervention may affect the interest rate risk profile over the course of the time horizon. Although most economic capital models are calibrated over a one-year holding period, many banks that use simulations will run multi-year simulations in order to value those instruments held at the one-year horizon which are not valued via closed form analytical formula.

\section{Main challenges for the measurement of interest rate risk in the banking book}

\section{Optionality in the banking book}

One of the most fundamental challenges in the measurement of interest rate risk in the banking book is the identification and incorporation of non-linear risk deriving from long-dated fixed-income obligations with embedded options for the borrower to prepay, frequently without penalty, and from the embedded options in non-maturity deposits.

Prepayment risk options are the predominant form of embedded optionality on the asset side of the balance sheet. Consumer loans, mortgages, and mortgage-backed securities (MBSs) are examples of assets with prepayment risk. Prepayment risk arises because borrowers have a call option on the loans: for example, in the case of fixed-rate mortgages, borrowers will choose to exercise this option and prepay their mortgages as interest rates fall sufficiently below the contract mortgage coupon rates. Because of the prepayment option, the cash flows associated with a mortgage are uncertain and the expected life of a mortgage is much shorter than its stated maturity.

Since the rate of prepayments increases as rates fall (especially as they fall below the mortgage contract rate), the price-yield curve for mortgages exhibits negative convexity and price compression. This occurs because interest rate decreases do not produce increases in

39 There are different reasons underlying this serial correlation of interest rate risk factors returns: the bid-ask spreads, the discontinuity in trading volumes of some interest rate sensitive instruments, the structural factors of some markets (i.e. low thickness and liquidity), etc. 
the values of mortgages as large as those of option-free bonds. In addition, holders of mortgages are forced to invest the cash flows that are prepaid at a lower rate of interest. ${ }^{40}$ When interest rates increase above mortgage contract coupon rates, the speed of mortgage prepayments by borrowers slows. The rate increase produces an increase in the duration of mortgages and a steeper decline in the value of these instruments than is the case for option-free bonds. This occurs because holders of mortgages are not able to reinvest the expected principal cash flows at the higher interest rate because of slower actual prepayments. ${ }^{41}$ Prepayment risk is therefore related to the variability or uncertainty in the rate at which the borrowers will prepay, depending on the evolution of the interest rates. It should be observed that mortgages also contain a second type of embedded option, whereby borrowers have a put option to default on their mortgage loans. ${ }^{42}$

On the liability side of the balance sheet, the embedded options in non-maturity deposits are the most common. In effect, non-maturity deposits contain two embedded options: (i) the institution holds the option to determine the interest rate offered to depositors and when to change the rate; and (ii) the depositor holds the option to withdraw all or part of the balance in the deposit account at par. The first option makes the deposit behave as a floating-rate bond, while the second option allows the depositor to put the bond back to the institution. ${ }^{43}$ As such, non-maturity deposits can be viewed essentially as floating-rate, putable bonds. Moreover, the two embedded options induce a volume risk, which cannot be hedged directly since the volume is not traded in the market.

Although non-maturity deposits can be withdrawn by depositors on demand, most of these deposits stay at the institution for months or years. In addition, while banking institutions may change the offered deposit rates when market interest rates change, they do so with a lagged response, and by less than the full amount of the change in market rates (see paragraph c. below). This is particularly true when rates increase. The interaction between the two embedded options found in non-maturity deposits makes the valuation and interest rate sensitivity of these liabilities one of the most widely debated issues currently in measuring interest rate risk in the banking book.

Although optionality is an important issue, the degree of sophistication in the techniques used by the institutions varies, depending not only on the type of institution, but also on the evolution of the legislation and prevailing market practices in the jurisdictions.

Income simulation models, such as EaR, are generally unable to analyse option risk fully and generally are only accurate for the short-term (ie two to three years) earnings component. Economic value approaches, such as EVE, provide better measurements of exposures with embedded options. However, accurately representing these exposures requires the use of stochastic-path evaluation techniques, which are computationally demanding, and mostly developed in the jurisdictions were market practice makes the optionality issues, such as mortgage prepayment, more relevant. Standard practice is to use discounted cash flows on

40 Contraction risk is that part of prepayment risk that derives from the decrease in the duration of mortgages and the reinvestment risk associated with the speedup of prepayments resulting from a decline in interest rates within the negatively convex region of the price-yield curve.

41 Extension risk is that part of prepayment risk that derives from the increase in the duration of mortgages and the reinvestment risk associated with a rise in interest rates.

42 Typically, they will choose to exercise this option when the remaining loan balance exceeds the market value of the property. As such, mortgage lenders are essentially selling embedded American straddle options (ie combined call and put options) to mortgagors.

43 Holding other things equal, customer's options have an impact on both principal and interest cash flows, while issuer's options have a direct impact on interest cash flows only. 
those positions that have linear or highly uncertain valuation profiles, and use stochastic-path techniques on those parts of the balance sheet that have non-linear valuation profiles.

In such instances, most firms combine in simulation models stochastic interest rate modelling techniques with behavioural assumptions on prepayments and on decisions to remain customers or not (deposit modelling or credit card customer retention modelling). A prepayment model must not only be able to predict current prepayment speeds, but also expected future prepayment speeds, which are largely a function of expected future mortgage interest rates. Larger institutions use more sophisticated statistical prepayment models to forecast prepayment speeds and account for the statistical relationships among the factors that drive prepayments. A modelling approach is required in which prepayment models are often combined with a term structure model of interest rates and dynamic simulation models, in producing mortgage valuations based on option-adjusted spreads. The prepayment/non-maturity deposit modelling may be carried out at local business level, to generate sensitivity to rate shocks at various stress levels, producing different prepayment/customer retention forecasts across interest rate shocks. Incorporating such assumptions should involve also considering model uncertainty on those assumptions, and incorporating a measure of model risk (eg prepayment error risk).

Industry use of competing risks models for mortgage prepayment and default is in its infancy, although several of the largest institutions have embraced this approach.

\section{Banks' pricing behaviour}

An important aspect of interest rate risk modelling is the effective responsiveness of individual bank interest rates to changes in market rates. The measurement of the interest rate risk of banking book items requires: (i) a model for the analysis of the persistence of the volumes of different non-maturity banking products; and (ii) a model for the determination of bank interest rates, taking into account general market conditions, customer relationships, bank commercial power, and optimal commercial policies.

The degree by which the interest rates set by banks react to market rates (interest rates pass-through) may depend on individual bank characteristics and may differ for different products. Changes in market interest rates may also result in changes in banks' interest rate policy, driven by changes in the competitive environment and the need to defend market share. $^{44}$

A typical finding in the literature is that banking interest rates pass-through is relatively slow and heterogeneous across both products and countries. It is slower for retail banking products (eg deposits, consumer loans, mortgages) than for corporate products; short-term products are more responsive than long-term products. ${ }^{45}$ Individual bank characteristics, such as the bank's liability structure, its liquidity and capitalisation position or the proportion of long term lending, are also relevant for interest rate determination; heterogeneity in the banking rates pass-through exists only in the short run. ${ }^{46}$ There is also some evidence of asymmetries in the interest rate pass-through, existing also in the short run: banks adjust

\footnotetext{
44 As such, some banks may not regard such policy changes as part of their interest rate risk, but rather as part of business risk.

45 For Europe, see Campa and Gonzales-Minguez (2006).

46 Gambacorta (2007)
} 
their loan lending rate faster during periods of monetary tightening, and their deposit rates faster during periods of monetary easing. ${ }^{47}$

A relevant aspect for determining bank interest rates is the pricing for credit risk, which influences the duration of bank loans and represents a "spread duration" component with a non-marginal effect on economic value, especially on longer term loans. To determine the price of credit risk applied on different banking products would ultimately require a pricing rule that links the credit spread to changes in macroeconomic conditions and interest rate variations. ${ }^{48}$ This also indicates that interest rate risk on the banking book is not independent from credit risk, and that interest rate stress scenarios should also incorporate the possible interaction of interest rate and credit risk factors.

\section{The choice of stress scenarios}

Stress testing is commonly used in interest rate modelling as a way to complement the complexities of interest rate risk systems with transparent interest rate shocks. As such, stress test results serve as a benchmark risk measure. ${ }^{49}$

Following the guiding principles of the Basel Committee, the current regulatory choice of a stress scenario focuses on parallel shifts in the yield curve of $+/-200$ basis points. ${ }^{50}$ The Committee acknowledges that the parallel shifts of $+/-200$ basis points are relatively simplistic, but it argues that these shocks appear to adequately cover volatilities across G10 countries, even though the appropriateness of the proposed shock needs to be monitored on an ongoing basis, and recalibrated should the rate environment shift materially. ${ }^{51}$

47 Gambacorta and lannotti (2007).

48 The price of credit risk varies with the counterparty credit rating in a away which is also influenced by the level of interest rates and more generally by the position in the economic cycle, especially if the banks adopt forward-looking economic capital calculations and provisioning and pricing policies.

49 The Committee on Global Financial Stability survey on stress testing (CGFS, 2005) reveals that a majority of banks run interest rates risk stress tests. Popular historical scenarios are the bond market sell-offs in 1994 and 2003; the Asian crisis in 1997, LTCM and Russia in 1998, or September 11, 2001. Hypothetical scenarios look at changes in the national or global economic outlook, increases in inflation expectations or unexpected changes in monetary policy. Scenarios generally cover environments where not only the level but also the slope and curvature of the yield curve are changing.

50 The Basel Committee (BCBS, 2004) has suggested several guiding principles for the selection of interest rate risk scenarios. The three most important are: the rate shock should reflect a fairly uncommon and stressful rate environment; the magnitude of the rate shock should be significant enough to capture the effects of embedded options and convexity within bank assets and liabilities so that underlying risk may be revealed; and the rate shock should be straightforward and practical to implement, and should be able to accommodate the diverse approaches inherent in single-rate-path simulation models and statistically driven value-at-risk models for banking book positions. As a practical guidance, in addition to considering 200 bps scenarios, the Committee also suggests looking at parallel shifts using the 1st and 99th percentile of observed interest rate changes with a one year horizon and five years of data.

51 Further, the Committee argues that, "while more nuanced rate scenarios (such as twists and turns in the yield curve) might tease out certain underlying risk characteristics, for the more modest objectives of supervisors in detecting institutions with significant levels of interest rate risk, a simple parallel shock is adequate. Such an approach also recognises the potential for spurious precision that occurs when undue attention to fine detail is placed on one aspect of a measurement system without recognition that assumptions employed for certain asset and liability categories, such as core deposits, are by necessity blunt and judgmental. Such judgmental aspects of an interest rate risk model often drive the resulting risk measure and conclusion, regardless of the detailed attention paid to other aspects of the risk measure."(Annex 3, para7, BCBS, 2004). 
The benefits of using simple interest rate shocks of $+/-200$ basis points are that these shocks are very simple and easy to communicate and that it is easier to compare the impact of these shocks on different portfolios. The drawbacks are that the shocks are not probabilistic and hence very hard to integrate into economic capital models based on $\mathrm{VaR}^{52}$ it is not necessarily sensitive to the current rate or economic environment; it doesn't take into account changes in the slope or curvature of the yield curve; and that it doesn't allow for an integrated analysis of interest rte and credit risk on banking book items.

Among the possible developments are: (i) scenarios based on historical distributions; (ii) scenarios based on principal component (PC) decomposition of the yield curve; (iii) scenarios based on the GARCH models; (iv) scenarios based on options; (v) scenarios based on macroeconomic factors; and (vi) scenarios linking credit and interest rate risk.

The suggestion in BCBS (2004) to use the 1st and 99th percentile of the observed interest rate changes over the last five years would be an easy way to look at a probabilistic scenario. However the historical distribution is backward-looking, which is inherently problematic for a forward-looking risk measurement. For example, given long interest rate cycles it may be the case that there are limited observations in one direction.. It should also be observed that the empirical distribution generally does not include both a plus and minus 200 basis points shock.

\section{(ii) Scenarios based on principal component decomposition of the yield curve}

A possible solution is to build a scenario simulation procedure based on PC decomposition of the yield curve in order to produce realistic scenarios of interest rates changes along various points of the term structure. ${ }^{53}$

The PC distribution functions are used in a Monte Carlo simulation in order to reproduce the correlation observed between the original risk factors. The usual assumption is that the PC are normally distributed; some recent work has applied a non-parametric simulation to account for the fact that PCs are skewed and heavy-tailed, recovering the empirical distribution through a kernel density estimation. ${ }^{54}$

In the context of PC representation, stress testing analysis can be performed by changing the volatility of interest rates along the yield curve and/or the correlation structure of the data. Correlation can be stressed by modifying the matrix of factor weights (the so called factor loadings), while assuming constant volatility. Conversely, one can shock the volatility of interest rate changes while maintaining the matrix of factor loading fixed at historical values.

The main advantage of this simulation procedure is that it assigns a level of confidence to all plausible scenarios (in terms of percentiles of the simulated distributions). The plausibility of

52 Even though the scenario has been calibrated on the $1^{\circ} / 99^{\circ}$ percentile of observed interest rate changes.

53 In the PC representation, interest rate changes at different maturities are expressed as a function of the new risk factors PCs, where the weighting coefficients (the so called "factor loading") capture the correlation in the system. The factor loadings account for the contribution of each risk factor to the overall variance. The PC decomposition of the yield curve usually reveals the existence of three underlying risk factors explaining a large part of total variance (around $95 \%$ ): the parallel shift of the yield curve; the tilt or rotation; the twist, that is a change in the curvature.

54 See Fiori and lannotti, 2007. 
scenarios is derived from the calibration of the procedure to the correlation structure observed in the market.

Simple autoregressive (AR) models with GARCH effects could be used to simulate the evolution of individual interest rates over a specific horizon. Such an approach would be forward looking and partially condition on the current environment in terms of level and volatility. At the same time it is relatively easy to implement.

\section{(iv)}

\section{Scenarios based on options}

A distribution of future changes of interest rates could also be extracted from options. The key (and so far not successfully solved) problem for such an approach is to translate the riskneutral PDs (necessary for trading and pricing) to real-world or physical PDs (important for risk management). ${ }^{55}$

\section{Scenarios based on macroeconomic factors}

Similar to credit risk models, it is conceptually possible to simulate a distribution of future yield curve changes based on macroeconomic fundamentals. ${ }^{56}$ Whereas there has been much progress in this field, explanatory power of macroeconomic factors remains weak and forecast and estimation errors are substantial. Even though these models could be used to condition changes on the current and future macroeconomic environment, technical difficulties could impede a consistent use of these models for economic capital calculation.

\section{(vi) Scenarios linking credit and interest rate risk}

It is a well established fact that interest rates are an important negative driver of the credit quality of banks' assets - one indication that credit risk and interest rate risk in the banking book are interdependent. ${ }^{57}$ The integration of credit and interest rate risk requires a sophisticated framework. First, the loss distribution of credit risk must condition on the macro and interest rate environment. Second, decreased net interest income due to default must be taken into account. Finally, for an earnings perspective, future cash flows need to be simulated. This necessitates a robust framework to price assets in the future conditional on the simulated macro and interest rate environment.

\section{Banking versus trading book}

The exclusion of the trading book from the measurement of interest rate risk eliminates the problem of double counting arising from the presence of a market risk requirement for interest rate sensitive positions held in the trading book. However it should be pointed out that the problem of double counting does not preclude the possibility that the exposures in the trading book and in the banking book offset each other.

55 It has to be noted however that for stochastic-path modelling, risk neutral implied volatilities are necessary to validate the model by checking for convergence to market prices at a reasonable Option Adjusted spread (OAS), a key validation test for mortgage models.

56 See for example Ang and Piazzesi (2003), Cochrane and Piazzesi (2006). Rudebusch and Williams (2007) provide an up-to date survey of the literature linking macro factors to yield curves.

57 Drehmann et al (2007) show that interactions between credit risk and interest rate risk can indeed be substantial and should be taken into account. 
In certain cases, the interest rate risk exposure of the trading book compensates partially the exposure of the banking book. For example, it is possible that the trading book has a short position with respect to interest rate shocks (in the sense that a rise in interest rates causes an increase in the economic value of the trading book), while the position in the banking book is long with respect to interest rate shocks (in the sense that a rise in interest rates causes a decrease in the economic value of the banking book). In cases such as this, it might be appropriate to consider the net exposure of the entire balance sheet. 


\section{Annex 4}

\section{Members of the Risk Management and Modelling Group}

Chairman:

Belgium:

Canada:

France:

Germany:

Italy:

Japan:

Luxembourg:

Netherlands:

Singapore:

Spain:

Sweden:

Switzerland:

United Kingdom:

United States:

EU Commission:

Financial Stability Institute:

Bank for International Settlements:
Mr Klaas Knot

Ms Claire Renoirte

Mr Richard Gresser

Mr Olivier Prato

Mr Nicolas Peligry

Mr Jochen Flach

Mr Tobias Fritsche

Mr Pierpaolo Grippa

Ms Simonetta Iannotti

Mr Masaki Bessho

Mr Takao Miyamoto

Mr Claude Wampach

Mr Jurgen Willemsen

Mr Shaji Chandrasenan

Mr Luis Gonzalez-Mosquera Mr Jesus Ibanez

Ms Malin Omberg Mr Lars Söderlind

Mr Martin Sprenger

Mr Alan Cathcart

Mr Miguel Browne

Mr Mike Carhill

Mr Jonathan Jones

Ms Robin Lumsdaine

Mr James Mahoney

Mr Martin Spolc

Mr Juan Carlos Crisanto

Mr Konstantinos Tsatsaronis Mr Mathias Drehmann

Mr Neil Esho

Mr Steven Friedman 


\section{References}

Akhavein, J D and A E Kocagil (2005): "A comparative empirical study of asset correlation", Fitch Ratings: Quantitative Financial Research Special Report, 14 July.

Ang, A and M Piazzesi (2003): "A no-arbitrage vector autoregression of term structure dynamics with macroeconomics and latent variables", Journal of Monetary Economics, vol 50 , no 5 .

Artzner, P, F Dalbaen, J M Eber and D Heath (1999): "Coherent measures of risk", Mathematical Finance, no 9, pp 203-228.

Bangia, A, F X Diebold and T Schuermann (2000): "Rating migration and the business cycle, with applications to credit portfolio stress testing", The Wharton School, working paper 00-26.

Bank of Japan (2005): Advancing Integrated Risk Management, http://www.boj.or.jp.

Bank of Japan (2007): Economic Capital Workshop Summary Record, http://www.boj.or.jp.

Basel Committee on Banking Supervision (1999): Credit risk modelling: current practices and applications, Basel, April.

July.

(2004): Principles for the management and supervision of interest rate risk, Basel,

(2005a): "Update on work of the Accord Implementation Group related to validation

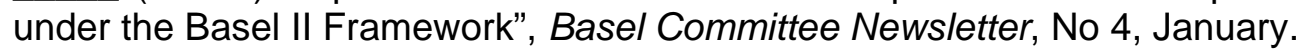

May.

(2005b): "Studies on the validation of internal rating systems" Working Paper, no 14,

(2009): Guidelines for computing capital for incremental risk in the trading book, Consultative Document, Basel, January.

Berkowitz, J (2000): "Testing Density Forecasts, with Applications to Risk Management", University of California, December, mimeo.

Black, F, E Derman and W Toy (1990): "A one-factor model of interest rates and its application to treasury bond options", Financial Analysts Journal, vol 46.

Black, F and P Karasinski (1991): "Bond and Option Pricing when Short Rates are Lognormal", Financial Analysts Journal, vol 47.

Brace, Al D Gatarek and M Musiela (1997): "The Market Model of Interest Rate Dynamics", Mathematical Finance, vol 7.

Breuer, T, M Jandacka, K Rheinberger and M Summer (2008): "Regulatory capital for market and credit interaction: is current regulation always conservative?", forthcoming, Journal of Banking and Finance.

Burns, R L (2004): "Economic Capital and the Assessment of Capital Adequacy", Supervisory Insights, vol 1, no 2, pp 5-16.

Burtschell, X, J Gregory and J P Laurent (2007): Beyond the Gaussian Copula: Stochastic and Local Correlation, January, mimeo. 
Campa, J M and J M Gonzalez Minguez (2006): "Differences in exchanges rate pass-through in the euro area", European Economic Review, vol 50.

Cochrane, J H (2007): "Commentary", Federal Reserve Bank of St Louis Review, July/August.

Committee of the Global Financial System (2005a): Stress testing at major financial institutions: survey results and practice, Basel, January.

January.

(2005): The role of ratings in structured finance: issues and implications, Basel,

Cox, J C, J E Ingersoll and S A Ross (1985): "A theory of the term structure of interest rates", Econometrica 53, pp 385-467.

Crouhy, M, D Galai and R Mark (2006): The Essentials of Risk Management, McGraw-Hill.

Dai, Q, and K J Singleton (2000): "Specification Analysis of Affine Term Structure Models", Journal of Finance, vol 55.

Das, S R, D Duffie, N Kapadia and L Saita (2007) "Common failings: how corporate defaults are correlated", Journal of Finance, vol LXII, no 1, February.

Davis, M and V Lo (2001): "Infectious Default", Quantitative Finance, vol 1, no 4, pp 382-387.

De Nederlandsche Bank (2005): Guidelines on Interest Rate Risk in the Banking Book, Amsterdam.

Diebold, F X, G D Rudebush and S B Arouba (2006) "The macroeconomy and the yield curve: a dynamic latent factor approach", Journal of Econometrics, vol 131.

Dimakos X K and K Aas (2004): "Integrated risk modelling”, Statistical Modelling 4, pp. 265277.

Drehmann, M, S Sorensen, and M Stringa (2008): "The integrated impact of credit and interest rate risk on banks: An economic value and capital adequacy perspective", Bank of England Working Paper 339.

Duffie, D, A Eckner, G Horel and L Saita (2006): "Frailty correlated default", October 19, mimeo.

Duffie, D, L Saita and K Wang (2005): "Multi-period corporate default prediction with stochastic covariates", September, mimeo.

Duffie, D, and D Lando (2001): "Term structures of credit spreads with incomplete accounting information", Econometrica, vol 69, no 3, pp 633-664.

Egloff, D, M Leippold and P Vanini (2004): “A simple model of credit contagion”, mimeo.

Fabozzi, F (2000): Bond Markets, Analysis and Strategies, Fourth Edition, Prentice Hall, New Jersey.

Fender, I and J Kiff (2004): "CDO rating methodology: Some thoughts on model risk and its implications", BIS Working Paper, no 163, Basel, November. 
Fermanian, J D and M Sbai (2005): A comparative analysis of dependence levels in intensity based and Merton style credit risk models.

Fiori, R and S Iannotti S (2007): "Scenario based Principal Component Value-at-Risk: an application to Italian banks' interest rate risk exposure", Journal of Risk, vol 9, no 3, pp 6399.

Frerichs, H and G Löffler (2002): "Evaluating credit risk models: A critique and a proposal", May, mimeo.

Frey, R and A J McNeil (2003): "Dependence modelling, model risk and model calibration in models of portfolio credit risk", Journal of Risk 6(1).

Gambacorta L (2007) "How do banks set interest rates", European Economic Review, forthcoming.

Gambacorta L and S Iannotti (2007): "Are There Asymmetries in the Response of Bank Interest Rates to Monetary Shocks?", Applied Economics, forthcoming.

Heath, D, R Jarrow and A Morton (1992): "Bond Pricing and the Term Structure of Interest Rates: A New Methodology", Econometrica, vol 60.

Hull, J C (2007): Risk management and financial institutions, Pearson Prentice Hall, New Jersey.

IFRI and CRO Forum (2007): Insights from the Joint IFRI/CRO Forum Survey on Economic Capital Practice and Applications.

IACPM and ISDA (2006): Convergence of Credit Capital Models.

Jarrow, R A and F Yu (1999): "Counterparty risk and the pricing of defaultable securities," September, mimeo

Jarrow, R A and F Yu (2001): "Counterparty risk and pricing of defaultable securities", Journal of Finance, vol 53, pp 2225-2243.

Lopez J A and M R Saidenberg (1999): "Evaluating Credit Risk Model", Federal Reserve Bank of San Francisco, Working paper no 99-06.

McNeil, A, R Frey and Embrechts (2005): Quantitative Risk Management; Concepts, Techniques, and Tools. Princeton Series in Finance.

PriceWaterhouseCoopers (2005): Effective Capital Management: Economic Capital as an Industry Standard?

Rutter Associates LLC (2004): 2004 Rutter Associates Survey of Credit Portfolio Management Practices.

Rosenberg J V and T Schuermann (2006): "A general approach to integrated risk management with skewed, fat-tailed risks", Journal of Financial Economics, vol 9, no 3, pp 569-614.

Rudebusch, G D, and J C Williams (2007): "Forecasting recessions: The puzzle of the enduring power of the yield curve", Federal Reserve Bank of San Francisco, Working Paper, No 2007-16. 
Samuel (2008): "Disclosure of Economic Capital", Federal Reserve Bank of New York, Available from the author or Policy Department, Federal Reserve Bank of New York, email: Jeffrey.Samuel@ny.frb.org. April 18.

Tarashev, N and H Zhu (2007): "Modelling and calibration errors in measures of portfolio credit risk", BIS Working Paper, Number 230. 